\title{
Administração política e políticas públicas: em busca de uma nova abordagem teórico-metodológica para a (re)interpretação das relações sociais de produção, circulação e distribuição
}

REgINALDO SOUZA SANTOS

Universidade Federal da Bahia / Escola de Administração, NúCleo de Pós-Graduação da (NPGA/EAUFBA), SALVAdor - BA, BRASIL

Elizabeth MATOS RiBEIRO

Universidade Federal da BAHIA / Escola de AdMinistração (EAUFBA), SAlVAdor - BA, BRASIL

MÔNICA MATOS RIBEIRO

Universidade do Estado da Bahia / Departamento de Clência Humanas, CAMpus V, SANTo ANTÔnio de Jesus - BA, BRASIL

FABiane louise Bitencourt Pinto

Universidade Federal de Minas Gerais / Centro de Pós-Graduação e Pesquisas em Administração (CEPEAD), Belo Horizonte - MG, Brasil

\begin{abstract}
Resumo
O objetivo central deste artigo é discutir o campo epistemológico da ciência da administração tomando como referência as contribuições da administração política, como base teórico-epistemológica e metodológica, para (re)interpretar, de forma crítica e contextualizada, as dimensões abstratas/conceituais (gestão) e empíricas (práticas gerenciais/gerência) das políticas públicas. Para dar conta da problemática epistemológica da administração, é fundamental reconhecer que se trata de um saber e uma prática social que não se vê, ainda, como campo do conhecimento autônomo. Como percurso metodológico, são apresentadas, inicialmente, as questões conceituais que fundamentam as bases da epistemologia e da metodologia da administração política que defende ser a gestão seu objeto científico e as organizações seu objeto de estudo privilegiado. Posteriormente, após a apresentação do campo de reflexão e ação da ciência da administração, os autores estabelecem estreito diálogo com outros campos científicos, em especial com a economia política. Por fim, são tecidas reflexões preliminares sobre contribuições que os estudos empíricos em administração política podem trazer para a (re)interpretação das relações sociais de produção, circulação e distribuição no capitalismo contemporâneo no que se refere à avaliação de políticas públicas.
\end{abstract}

Palavras-chave: Administração política. Epistemologia da administração. Avaliação de políticas públicas.

Political Administration and Public Policies: building a new theoretical and methodological approach to understand social relations of production, circulation and distribution

\section{Abstract}

The aim of this essay is to discuss the epistemological field of the science of administration, using the contributions of the Political Administration, as a theoretical-epistemological and methodological basis to understand, in a critical and contextualized way, the abstract/conceptual ('management') and empirical ('administration practices') dimensions of public policies. In order to address the administration epistemologic problem, it is crucial to recognize that administration is a social 'knowledge' and 'practice' that is still not perceived as an autonomous field of knowledge. As for the methodological path, the study presents the conceptual issues supporting the epistemological and methodological basis of the Political Administration, which defends that the 'management' is its 'scientific object' and the 'organization' its privileged 'object of study'. Subsequently, after broadening the understanding of the field of reflection and action of administration science, the authors establish a dialogue with other scientific fields, especially with Political Economy. Finally, the essay presents preliminary reflections on contributions that empirical studies in Political Administration can bring to understanding social relations of production, circulation and distribution in contemporary capitalism in terms of evaluation of public policies.

Keywords: Political Administration. Epistemology of Administration. Evaluation of Public Policies.

Administración Política y Políticas Públicas: en busca de un nuevo abordaje teórico-metodológico para la reinterpretación de las relaciones sociales de producción, circulación y distribución

\section{Resumen}

El objetivo central de este ensayo es discutir el campo epistemológico de la ciencia de la Administración, tomando como referencia las contribuciones de la Administración Política, como base teórico-epistemológica y metodológica para reinterpretar, de forma crítica y contextualizada, las dimensiones abstractas y conceptuales (gestión), así como las empíricas (prácticas gerenciales/gerencia) de las políticas públicas. Para dar cuenta de la problemática epistemológica de la Administración, es fundamental reconocer que se trata de un saber y práctica social que todavía no se ve como campo de conocimiento autónomo. En el trayecto metodológico se presentan, inicialmente, las cuestiones conceptuales que fundamentan las bases epistemológicas y metodológicas de la Administración Política, que defiende la gestión como su objeto científico y las organizaciones como su objeto de estudio privilegiado. Al ampliar la comprensión del campo de reflexión y acción de la ciencia de la Administración, los autores establecen un diálogo estrecho con otros campos científicos, en especial con la Economía Política. En las conclusiones, se presentan reflexiones preliminares acerca de las contribuciones que los estudios empíricos en Administración Política pueden aportar a la reinterpretación de las relaciones sociales de producción, circulación y distribución en el capitalismo contemporáneo, en lo que se refiere a la evaluación de las políticas públicas.

Palabras clave: Administración Política. Epistemología de la Administración. Evaluación de Políticas Públicas. 
Administração política e políticas públicas: em busca de uma nova abordagem teórico-metodológica para a (re)interpretação das relações sociais de produção, circulação e distribuição
Reginaldo Souza Santos | Elizabeth Matos Ribeiro Mônica Matos Ribeiro | Fabiane Louise Bitencourt Pinto

\section{INTRODUÇÃO}

Como tem sido apontado por diversos autores ${ }^{1}$, os avanços da administração como campo filosófico e científico ainda são embrionários. Nesse sentido, Serva (2013, p. 500) destaca que o "processo de institucionalização da administração como uma ciência" teve início em 1911, sob a liderança do pensamento tradicional da administração científica, defendido por Frederick Taylor e Henri Fayol, e desenvolveu-se, de modo acelerado e universal, como prática profissional ao longo de todo o século $\mathrm{XX}$ - e mantém-se firme nos dias atuais.

Entretanto, como sustentam diversos autores, ainda que haja evidências do reconhecimento do papel social da administração como campo profissional, sua aceitação tem permanecido limitada ao exercício das funções operacionais voltadas a atender, essencialmente, as exigências do desenvolvimento do sistema econômico. Esse esforço intelectual, originado nas elaborações mais sofisticadas de Taylor (1976) e Fayol (1916), tinha por objetivo central garantir as relações sociais de produção, circulação e distribuição, tendo como manifestação máxima desse pensamento (ideologia) o movimento doutrinário do management, como ressaltado por Vizeu (2010b). Dito de outra forma, Santos (2004) e Santos, Ribeiro e Chagas (2009) vão destacar que a administração nasce, portanto, como campo técnico subordinado aos princípios e objetivos determinados pela economia neoclássica. O que significa admitir que não se trata apenas de reconhecer que a administração ainda é um campo indefinido, carente de identidade como área do conhecimento particular ou específica, conforme definição de Japiassu (1992); mas grave, também, é reconhecer que tem aceitado, passivamente, o papel que lhe foi destinado historicamente como arena auxiliar da economia, das engenharias e até de outros campos do conhecimento, como as ciências sociais e humanas - especialmente da psicologia, sociologia, antropologia e ciência política, que têm tido expressiva atuação nos estudos sobre gestão das organizações (pública, privadas e sociais).

Inconformados com essa percepção tecnicista e limitada dos fenômenos administrativos, um grupo de professores da Universidade Federal da Bahia (UFBA) tem investido esforços na discussão e proposições espistemológicas das bases da cientificidade da administração. Ainda que essa discussão se inicie com a publicação do artigo "A administração política brasileira" (SANTOS e RIBEIRO, 1993), somente na década de 2000 se passou a investir, de modo sistemático no desenvolvimento das bases teórico-epistemológicos e metodológicas da administração política (SANTOS, 2004; SANTOS, RIBEIRO e CHAGAS, 2009). Mais recentemente, a partir de 2012, avançam no desenho de pesquisas empíricas com ênfase em metodologias que possibilitam avaliar, de forma crítica e contextualizada, as políticas públicas, rompendo com as abordagens que insistem em manter firmes os princípios que fundaram a administração científica - pautados na perpetração do conceito clássico de custo-benefício e expresso na defesa do aumento (ad infinitum) da produtividade do trabalho e no alcance da eficiência real e potencial da produção social (FISCHER, 1995, 2016; BOULLOSA, 2013; FARAH, 2011).

Entretanto, os principais e decisivos passos sobre esse esforço acadêmico foram dados no âmbito da formação em administração da UFBA, mediante a integração da abordagem sobre administração política na disciplina "Tópicos Especiais em Planejamento", entre 2000 e 2005. O resultado desse esforço foi a realização pelos estudantes, sob a orientação dos professores Reginaldo Santos e Elizabeth Matos, de uma revisão crítica sobre os estudos clássicos da administração pública, da administração científica e da economia política, com o objetivo de compreender como esses campos abordavam o pensamento administrativo à luz da administração política (SANTOS, 2004). Esse empenho acadêmico inicial foi fundamental por ter possibilitado, em primeiro lugar, integrar essa discussão e reflexão no âmbito da formação profissional em administração e, em segundo lugar, avançar em reflexões teóricas e epistemológicas sobre um campo pouco afeito a debates de caráter mais científico.

A conclusão desses primeiros estudos sobre administração política resultou no reconhecimento de que a administração configurava um campo do conhecimento indefinido, como já destacado. Segundo os autores (e professores) citados, essa

${ }^{1}$ Descacam-se especialmente as abordagens críticas que integram os estudos organizacionais (GUERREIRO RAMOS, 1989; REED, 1999; CUNHA, 2000; AKTOUF, 2001, 2004; FRANÇA FILHO, 2004; SERVA, 2013), os contributos dos estudos críticos em administração (ALVESSSON e WILLMOTT, 1992; FOURNIER e GREY, 2000; DAVEL e ALCADIPANI, 2003; MISOCZKY e ANDRADE, 2005; PAES DE PAULA, 2016), assim como as apreciações críticas à luz das ciências sociais de João Ubaldo Ribeiro (2006), da economia e da sociologia política, como o fizeram Maurício Tragtenberb (1971, 1989) e João Bernardo (2000), da filosofia política, como proposto originalmente por Ariston Azevedo e Paulo Sérgio Grave (2014), e da história, como fez Fábio Vizeu (2010a, 2010b), além de outras contribuições inspiradoras originadas por grupos de pesquisa de inspiração marxista, como os liderados por professores e pesquisadores da Universidade Federal de Minas Gerais (UFMG), da Universidade Federal Fluminense (UFF) e da Universidade Federal de Juiz de Fora (UFJF). 
Administração política e políticas públicas: em busca de uma nova abordagem teórico-metodológica para a (re)interpretação das relações sociais de produção, circulação e distribuição
Reginaldo Souza Santos | Elizabeth Matos Ribeiro Mônica Matos Ribeiro | Fabiane Louise Bitencourt Pinto

indefinição se manifestava, principalmente, pela inexistência de consenso entre os renomados estudiosos do campo, especialmente no que se refere a uma definição clara de seu objeto científico, de modo a investir em bases conceituais, epistemológicas e metodológicas que diferenciassem a administração da economia, principalmente da economia neoclássica².

Ao considerar uma disciplina ou área de conhecimento funcional comprometida, essencialmente, em atender as demandas técnicas do sistema socioeconômico capitalista, a administração abriu mão, historicamente, de ser uma disciplina ou campo do conhecimento autônoma. Entretanto, vale ressaltar que, ao defender que a ciência da administração é uma disciplina com capacidade científica, capaz, portanto, de dar conta de análises teóricas/abstratas e empíricas próprias dos fatos e atos administrativos ou dos saberes e práticas administrativas (CORREA e JURADO, 2003) - que refletem, portanto, seu fôlego filosófico e epistemológico -, não se nega a estreita correlação entre administração e economia - especialmente entre a administração política e a economia política. Como será aprofundado nas próximas seções, trata-se de dois campos que têm muito mais em comum do que as leituras superficiais têm sido capazes de dar conta, pois respondem, conjuntamente, pela concepção e execução de certo projeto de nação e/ou projeto de sociedade. Esse esforço comum tem-se caracterizado na reivindicação da capacidade histórica exigida pela economia e pela administração para garantir níveis de produção (política e técnica) eficientes dos meios que irão garantir o alcance (ideal e potencial) da materialidade social.

Nesse sentido, o que Santos (2004) e Santos, Ribeiro e Chagas (2009) defendem como administração política é um conceito que contribui justamente para oferecer à ciência da administração um status científico para que se qualifique não apenas para reproduzir modos voltados a melhorar e operacionalizar os meios de produção, mas também para se qualificar para pensar modos/padrões de condução das relações sociais de produção, circulação e distribuição. O que exige considerar que tanto a dimensão teórica (categorizada pelos autores como campo próprio da gestão, da concepção dos modos de administrar os negócios - públicos e privados) quanto o campo que reflete a dimensão técnica (categorizada como campo próprio da gerência ou das práticas gerenciais) e que, por estarem integrados e articulados de forma indissociável, dão à administração um caráter científico - como uma ciência social aplicada, como defendeu João Ubaldo Ribeiro (2006). Vale ressaltar que o autor citado vai destacar algo fundamental para que se possa avançar na discussão sobre a epistemologia da administração, ao denunciar que o primeiro esforço a ser empreendido no empenho de conferir cientificidade aos fenômenos e às práticas administrativas seria romper com a concepção positivista que orientava e ainda orienta as ciências sociais, reflexão aprofundada na próxima seção.

Ao admitir a estreita e relevante aproximação entre economia política e administração política, Santos (2004) e Santos, Ribeiro e Chagas (2009) trazem outra importante contribuição a esse debate e defendem que, enquanto a ciência econômica seria responsável por definir o que, por que e para que produzir - isto é, por definir os meios de produção e circulação e determinar as formas mais apropriadas aos interesses coletivos de distribuir os resultados dessa cultura social, caberia à ciência administrativa, pois, materializar as formas subjetivas e técnicas de administrar esse padrão de produção social idealizado coletivamente, assumindo, portanto, o desafio de definir como conduzir (administrar/gestar) e como colocar em prática (gerenciar) as relações sociais de produção, circulação e distribuição; atendendo, assim, aos propósitos definidos pelas relações complexas estabelecidas historicamente entre sociedade-Estado-mercado.

Assim, ao admitir que a administração é um campo científico próprio, mostra-se fundamental avançar na definição de metodologias de análise dos fenômenos administrativos, de modo a dotar essa área do conhecimento dos meios teóricos e metodológicos que permitam não apenas (re)interpretar a realidade organizacional e social, mas transformá-la. Nesse sentido, uma dos propósitos mais relevantes da administração política é dar esse campo condições cientificas para que possa assumir o papel como saber interpretativo e como saber emancipatório, como destacado por Paes de Paula (2016) e Santos (2017), que, inspirados nos estudos críticos em administração vão fazer uma revisão sobre as contribuições dos estudos organizacionais e dos estudos críticos em administração revelando aderência aos estudos da adminsitração.

A partir dessas considerações iniciais, este artigo tem por objetivo central:

${ }^{2}$ Naturalmente, não se pode negar as contribuições trazidas por relevantes autores clássicos, especialmente pelos primeiros estudos realizados por Dimock $(1937,1968)$ e Weber $(1974,2000)$, preocupados em delimitar, orientar e qualificar o desempenho da administração pública (dando destaque ao relevante papel que o Estado passava a assumir na economia de mercado), assim como pelos avanços trazidos por Taylor (1976) e Fayol (1916) à concepção da administração científica, área dedicada, como já ressaltado, a atender as demandas administrativas das emergentes organizações produtivas (SANTOS, 2004; SANTOS, RIBEIRO e CHAGAS, 2009; VIZEU, 2010a, 2010b; SERVA, 2013; PAES DE PAULA, 2016; SANTOS, 2017). 
Administração política e políticas públicas: em busca de uma nova abordagem teórico-metodológica para a (re)interpretação das relações sociais de produção, circulação e distribuição
Reginaldo Souza Santos | Elizabeth Matos Ribeiro Mônica Matos Ribeiro | Fabiane Louise Bitencourt Pinto

- Discutir o campo epistemológico da ciência da administração tomando como referência as contribuições da administração política por base teórico-epistemológica e metodológica para a elaboração de uma nova abordagem para a (re)interpretação das relações sociais de produção, circulação e distribuição no que se refere à avaliação de políticas públicas.

Considera-se que a administração política pode aportar relevantes contribuições para os estudos críticos em avaliação de políticas públicas, sendo uma das principais contribuições a possibilidade de integrar como dimensões de análises os aspectos políticos (gestão) e técnicos (gerência) que conformam os saberes e as práticas administrativas (CORREA e JURADO, 2003) como elementos indissociáveis de um mesmo processo e/ou prática social.

Para facilitar o entendimento, o texto foi estruturado em três seções, além desta introdução e das considerações finais:

1. A primeira seção traz uma síntese do conceito e das bases epistemológicas e metodológicas da administração política com ênfase na discussão dos conceitos de gestão e gerência, dando destaque à defesa de ser a gestão o objeto científico da ciência da administração e a gerência sua manifestação empírica. Nesse momento, também serão apresentadas as correlações entre os conceitos de administração política (gestão) e administração profissional (gerência) como categorias de análise centrais para os estudos da administração política.

2. Após essa discussão mais conceitual, o texto avança na segunda seção em uma reflexão sobre as contribuições da economia política para a definição e consolidação do conceito de administração política, entendidos como campos articulados e responsáveis conjuntamente pela concepção e execução da materialidade humana e social.

3. Por fim, a terceira seção traz uma discussão sobre as contribuições da abordagem teórico-epistemológica e metodológica da administração política para uma (re)interpretação, crítica e contextualizada, das relações sociais de produção, circulação e distribuição, tendo como ênfase a proposição de metodologia para avaliar políticas públicas.

Acredita-se que as provocações e reflexões destacadas ao longo deste artigo trazem uma relevante contribuição tanto para o reposicionamento dos estudos acadêmicos que tem sido empreendidos pela área da administração, como também porque pode interessar a outros campos do conhecimento, especialmente à economia, às ciências sociais, às engenharias, entre outras áreas/disciplinas que também têm investido esforços para compreender a complexidade dos fenômenos da gestão e das práticas gerenciais (em suas diferentes manifestações, políticas, técnicas e simbólicas).

\section{(RE)DEFININDO O CONCEITO DE GESTÃO E GERÊNCIA À LUZ DA TEORIA DA ADMINISTRAÇÃO POLÍTICA}

O conceito de gestão, como tem defendido diversos estudos (PAES DE PAULA, 2016; SANTOS, 2017), ainda é impreciso, amplo e diversificado. Na literatura corrente da área de administração a discussão se encontra em dois campos vistos como distintos: o da administração geral (denominada administração científica) e o da administração pública (GUIMARÃES, SANTOS, MELO et al., 2004). Nesse debate, observa-se outra imprecisão conceitual que tem sido perpetrada no meio acadêmico e profissional, que defende estar o conceito de administração pública mais próximo do campo da ciência política do que da administração científica. Esse argumento pode ser mais bem visto na tese defendida por Carlos Matus (1993) ${ }^{3}$, sintetizada no chamado "Triângulo de Governo", que tem constituído referência para muitos estudos recentes em políticas públicas, especialmente na América Latina e no Brasil. Essa confusão demonstra, portanto, como ressaltam Santos (2004) e Santos, Ribeiro e Chagas (2009), que a administração é um campo do conhecimento não só indefinido, mas carente de identidade, o que confirma ainda necessitar de "reconhecimento e legitimação da comunidade científica" (SANTOS, 2017, p. 211).

Com o objetivo de aprofundar esse debate e contribuir para a discussão da cientificidade da administração, os autores citados defendem ser a administração um campo do conhecimento autônomo. Essa afirmação parte do pressuposto de que a qualidade da ciência da administração está vinculada à sua dimensão política (abstrata) dos atos e fatos administrativos e que tem por objeto científico a gestão e não a organização, como defendem outras literaturas, a exemplo da defesa feita por França Filho (2004).

${ }^{3} \mathrm{~A}$ tese de Carlos Matus é relativamente simples: passa pelo reconhecimento de que a capacidade de governo revela a articulação dinâmica entre a existência de projetos de governo, de determinado grau de governabilidade do sistema e da capacidade de governo, de modo a conduzi-lo aos objetivos contemplados nos projetos. 
Administração política e políticas públicas: em busca de uma nova abordagem teórico-metodológica para a (re)interpretação das relações sociais de produção, circulação e distribuição
Reginaldo Souza Santos | Elizabeth Matos Ribeiro Mônica Matos Ribeiro | Fabiane Louise Bitencourt Pinto

Partindo dessa conjectura defendem, então, as bases do que denominam administração política. E para defender a autonomia científica da administração os estudiosos do campo da administração política definem que as bases desse novo conceito 4 estão justamente na responsabilidade de definir e executar uma dada concepção (espacial e temporal) de gestão das relações sociais de produção, circulação e distribuição. Nesse sentido, ao identificar a gestão como objeto científico da administração, os autores supracitados se identificam com os argumentos defendidos pelos estudos críticos em administração, bem como com outros esforços que tem sido empreendidos por grupos de estudos ajuizadores da epistemologia e sociologia desse campo. Merecem ser destacadas as relevantes contribuições trazidas por João Ubaldo Ribeiro (2006) quando escreve, nos anos 1960, como resultado de seus estudos de pós-graduação em administração pública, uma dissertação intitulada Administração e política. Nesse estudo, o literato defende ser a administração uma ciência social aplicada que se revelava como um campo científico diferenciado tanto por carregar um elevado grau de subjetividade (próprio de seu papel político) como por ter o compromisso com o exercício de uma prática administrativa (prática social) contextualizada.

Os debates internacionais e nacionais sobre a relação entre administração e política estão presentes na área de administração, particularmente nos estudos clássicos sobre administração pública, assim como no campo da ciência política, há mais de um século ${ }^{5}$. Como destaca Filippin (2017), tais estudos podem ser divididos em três abordagens principais: a) a dicotômica, que retrata a correlação entre administração e política como fenômenos distintos e separados; b) a complementar ${ }^{6}$, que defende haver alguns pontos de ligação entre administração e política, considerando, pois, as práticas administrativas fenômenos políticos; e c) a representada pelos estudos em administração política, que avança nesse debate ao admitir que administração é política, como tem sido defendido por Ribeiro (2006), Santos (2004), Santos, Ribeiro e Chagas (2009) e Azevedo e Grave (2014).

Ainda que se observe a predominância da primeira abordagem (a dicotômica), considera-se neste artigo haver um importante avanço nesse debate a partir da proposta teórica e epistemológica defendida pelos administradores políticos, que admitem não apenas que administração e política são conceitos interligados, mas afirmam, definitivamente, existir um campo do conhecimento que se intitula administração política. Nesse sentido, asseguram que a característica central dessa área de saberes e práticas administrativas, como definido por Correa e Jurado (2003), está tanto em sua dimensão política (teórica) como em sua dimensão empírica. Ao admitir a subjetividade que caracteriza as ações administrativas (e que carregam em si o fenômeno político), os autores supracitados asseveram, pois, que o campo científico da administração se capacita para se revelar um campo do saber complexo e multidisciplinar, responsável tanto por definir a concepção de um dado modo de administrar (de conduzir a gestão de uma organização e/ou sociedade) como também por determinar as bases técnicas para sua plena e efetiva execução (por meio das práticas gerenciais).

Ao esforço de integrar as dimensões subjetivas (políticas) e objetivas (práticas) que conformam a ciência da administração, como campos indissociáveis de um mesmo processo social, os estudos da administração política agregam outro conceito fundamental, definido como campo de reflexão e ação próprio da administração profissional. Com essa abordagem mais técnica, referente às concepções e dinâmicas que darão sustentação e sentido à execução de certo padrão de administração política, Santos (2004) e Santos, Ribeiro e Chagas (2009) completam o arcabouço teórico-epistemológico e metodológico da administração política, contribuindo para recolocar a administração em um patamar mais elevado do que se define como base de sua cientificidade, como mostra a Figura 1.

\footnotetext{
${ }^{4}$ Iniciados em 1993, os estudos na área da administração política contam hoje com o apoio de diversos estudantes dos cursos de graduação e pós-graduação em administração da UFBA e de outros professores e pesquisadores vinculados a diversas instituições nacionais e internacionais: Escola Brasileira de Administração Pública e de Empresas da Fundação Getulio Vargas (FGV EBAPE), Escola de Administração de Empresas de São Paulo da Fundação Getulio Vargas (FGV EAESP), Universidade Estadual de Santa Cruz (UESC), Universidade Estadual do Sudoeste da Bahia (UESB), Universidade Federal de Alagoas (UFAL), Universidade Federal de Campina Grande (UFCG), Universidade Estadual da Paraíba (UEPB), Universidade Federal do Ceará (UFCE), Universidade Estadual do Ceará (UECE), Universidade Federal de Minas Gerais (UFMG), Universidade de Brasília (UnB) e Instituto Superior de Economia e Gestão da Universidade Técnica de Lisboa (ISEG/UTL).

${ }^{5}$ Foram pioneiros os trabalhos de Woodrow Wilson (2005), com o livro The study of administration, de 1887; Frank Goodnow (2003), com o livro Politics and administration, de 1900; e Max Weber (1993, 2011), com as obras Parlamento e governo na Alemanha reordenada: crítica política do funcionalismo e da natureza dos partidos, de 1918, e Ciência e política: duas vocações, de 1919.

${ }^{6}$ Além de outros autores, merecem ser destacados aqui os estudos de Dwight Waldo (1948), ao apresentar importantes contribuições para a interpretação revisionista da literatura sobre política e administração, indicando objeções à visão diconômica e buscando as raízes históricas da dicotomia. É considerado um dos autores mais influentes da área da administração pública, oferecendo importantes reflexões sobre o assunto em questão.
} 
Administração política e políticas públicas: em busca de uma nova abordagem teórico-metodológica para a (re)interpretação das relações sociais de produção, circulação e distribuição
Reginaldo Souza Santos | Elizabeth Matos Ribeiro Mônica Matos Ribeiro | Fabiane Louise Bitencourt Pinto

Figura 1

Bases teórico-epistemológicas da administração política

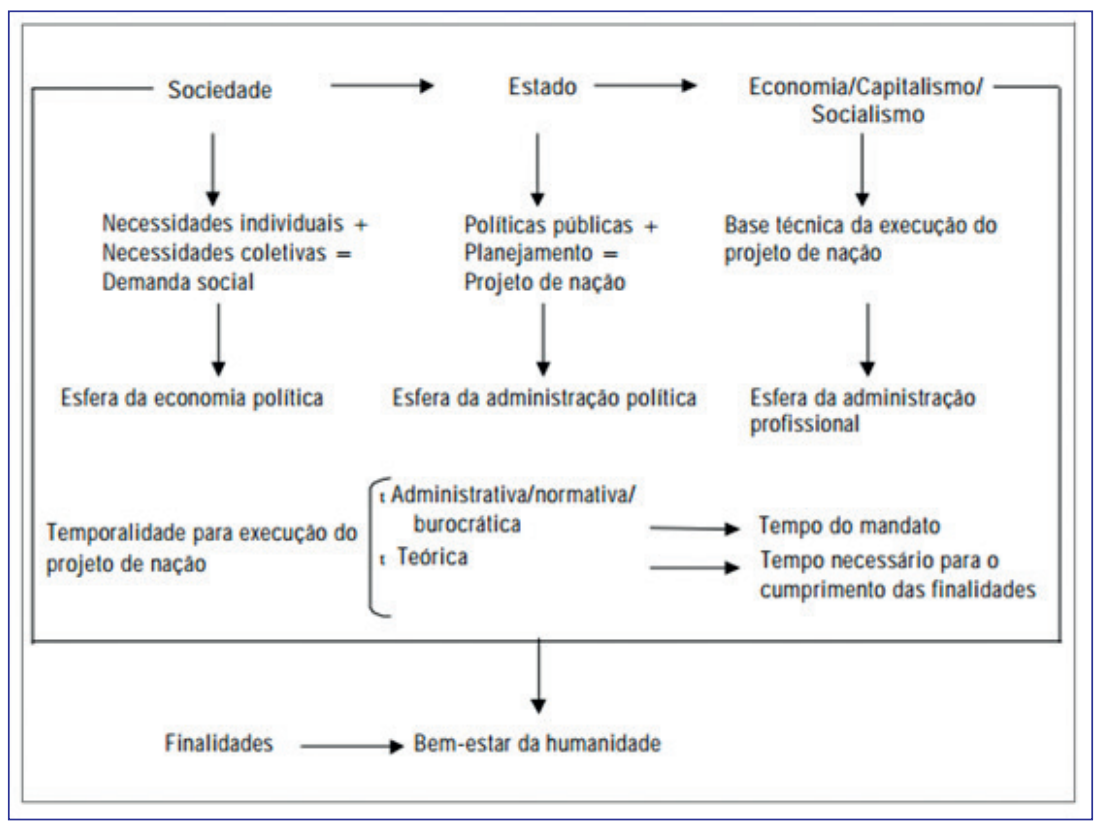

Fonte: Santos (2004, p. 48)

Ao integrar o conceito de administração profissional, os estudos da administração política conseguem não apenas contribuir para consolidar as bases filosóficas (AZEVEDO e GRAVE, 2014), epistemológicas e sociológicas (RIBEIRO, 2006; SERVA, 2013) como também integrar nessa abordagem científica os importantes subsídios históricos trazidas pelo movimento da administração científica ${ }^{7}$. Essa definição é fundamental para o entendimento do conceito de gerência como base técnica responsável por garantir a execução plena de certa concepção/padrão de gestão. Nesse sentido, Santos (2004, p. 44) (re)define o conceito de gerência como "campo responsável pela dimensão abstrata e analítica da gestão, isto é, a dimensão técnica que garante a capacidade técnica para a execução de um dado projeto/concepção administrativa", assumindo, portanto, um papel complementar e indissociável do ato e fato administrativo.

Como ressalta o autor,

[...] enquanto a capacidade de gestão (Administração Política), em sua dimensão abstrata e empírica, implica a definição do modo de articulação da concepção (conteúdo/forma) com o movimento (dinâmica) para o alcance da finalidade e objetivos administrativos, a capacidade gerencial pauta-se na concepção e implantação dos microprocessos administrativos que orientam a qualidade da implantação do padrão de gestão de uma dada sociedade ou organização. (SANTOS, 2004, p. 44)

Para os autores, enquanto a gestão reflete a dimensão política dos saberes administrativos (CORREA e JURADO, 2003) a gerência reflete a dimensão técnico-instrumental ou as práticas resultantes de um dado saber. Afirmam, pois, que a interação entre as duas dimensões se encontra no fato de que a gestão responde pelos aspectos mais abstratos/teóricos da administração e a gerência atende pela concepção e viabilização de sua operacionalidade, isto é, pelo que denominam engenharia dos processos de gestão8.

\footnotetext{
${ }^{7}$ Nascida no bojo das transformações ocorridas no campo da gestão do capitalismo da segunda metado do século XIX, a administração científica sofreu forte influência da economia neoclássica, particularmente as vinculadas à área da microeconomia, também nascente. Assim, essa nova ciência irá emergir em um contexto de negação profunda do papel da dimensão política ou subjetiva, tanto no âmbito da economia como no âmbito da gestão, estando seu papel vinculado, fundamentalmente, aos controles dos processos de trabalho - materializado nos estudos desenvolvidos por Taylor sobre o controle dos tempos e movimentos do trabalho e qualificado nas descrições das funções básicas da administração definidas por Fayol. Então, a administração científica vai emergir e consolidar-se como campo auxiliar da economia, voltado a garantir o ordenamento mais favorável dos fatores produtivos, com o objetivo de elevar sua eficiência, sobrando muito pouco espaço para refletirem sobre questões sociais, políticas ou ideológicas.

${ }^{8}$ Segundo Santos (2004, p. 45), a administração profissional compreende "todos aqueles profissionais [e áreas técnicas] que, direta ou indiretamente, são responsáveis pela execução do Projeto de Organização ou Projeto de Nação - o economista, o médico, o pedagogo, o filósofo, o arquiteto, o administrador,
} 
Administração política e políticas públicas: em busca de uma nova abordagem teórico-metodológica para a (re)interpretação das relações sociais de produção, circulação e distribuição
Reginaldo Souza Santos | Elizabeth Matos Ribeiro Mônica Matos Ribeiro | Fabiane Louise Bitencourt Pinto

Com base nessa concepção, pode-se inferir que a separação entre gestão e gerência, entre política e técnicas administrativas, só tem sentido metodológico e pedagógico para orientar a formação profissional em administração. Segundo a abordagem da administração política, não há possibilidade teórica e empírica de separar essas duas dimensões, pois tal esforço implicaria eliminar a essência ou a virtude que caracteriza, como destacado por Azevedo e Grave (2014), a ação política do bom governar, a administração.

Com o propósito de clarificar essa discussão, Santos, Ribeiro e Chagas (2009, p. 29-30) fazem uma distinção clara entre os conceitos de administração, gestão e gerência, destacando que, ainda que se complementem, têm significados e sentidos diferentes. Assim, ao definir as bases teórico-metodológicas da administração política reconhecem o significado de administrar como um substantivo composto formado pelo prefixo ad (preposição que significa para) e pelo núcleo ministrar (verbo que significa conduzir, orientar, dirigir). Concluem, portanto, que o vocábulo administrar, para os objetivos aqui tratados, representa o sentido de conduzir (algo) para algum lugar, ou seja, significa dirigir uma dada ação para o alcance de determinada finalidade. A partir dessa compreensão originária, tomando por base a etimologia, os autores avançam para compreender que a definição do ato e fato administrativo se manifesta em duas dimensões articuladas e integradas entre si, como já destacado e mais bem caracterizado aqui:

- A dimensão da gestão9: definida como a concepção das formas de condução das relações sociais de produção, circulação e distribuição, observadas em quaisquer níveis de organização humana (individual, organizacional e coletiva) e que assumem a dimensão de objeto científico da administração política; e

- A dimensão da gerência: é definida como a ação, o ato de fazer, a materialização daquilo que fora concebido no plano da gestão e que compreende a manifestação concreta do conceito de administração profissional.

Ao definir a administração política como campo teórico e epistemológico responsável pela concepção e execução de um dado padrão de gestão das relações sociais de produção, realização e distribuição - incluindo desde os projetos individuais até o projeto de nação ou projeto de sociedade - os autores defendem que esse novo campo científico integra, de modo indissociado, as dimensões de reflexão e ação administrativas, responsáveis por definir e aplicar métodos e técnicas que contribuam para melhorar os resultados dos negócios e da vida social (tomando-se, aqui, o sentido do pensamento grego clássico do bom governar).

Ainda que se idealize tratar-se de uma abordagem epistemológica crítica, capaz de construir, como ressalta Serva (2013, p. 502), "uma ciência com consciência", a administração política como uma abordagem teórica capaz de contribuir para (re) interpretar e (re)siginficar a realidade social e organizacional tem sido utilizada, como diversos outros esforços científicos, para preservar interesses dominantes ou para garantir a manutenção do status quo. Naturalmente, para os ideais críticos que fundamentam e mobilizam a origem desse movimento que busca uma epistemologia engajada e comprometida com a transformação das práticas sociais, a utopia de que esse esforço intelectual possa contribuir para o alcance do bem-estar da humanidade/sociedade mantém-se como orientador dos estudos que podem ser desenvolvidos com base nos princípios da administração política.

É importante ressaltar que a administração, a partir de uma compreensão mais ampliada trazida pela administração política, não pode se conformar em ser considerada apenas como mero instrumento técnico de práticas sociais pautadas em uma racionalidade utilitarista, conformando-se em exercer uma pretensa função de neutralidade do fazer humano e social. Ao contrário disso, os avanços produzidos pelos estudos epistemológicos críticos no campo da administração e dos estudos organizacionais, incluindo as contribuições da administração política, demonstra, como afirma Santos (2017, p. 225),

[...] que o conhecimento científico, em sua versão contemporânea, fundamenta-se em princípios que prezam pela totalidade universal dos saberes, independente das suas categorias e especializações. 0 fazer ciência significa estabelecer diálogos que vão da filosofia à estética, do local ao global, e do micro

\footnotetext{
o engenheiro, o pedreiro, o carpinteiro, o motorista, enfim, todos os profissionais requeridos para a construção [de um dado] projeto de sociedade". Ao reconhecer a dimensão técnica/instrumental da administração (administração profissional) como essencial para a execução do projeto de nação e de organização, Santos (2004) coloca em xeque a própria concepção de formação e ação do administrador (bacharel em administração), como área exclusiva para esse perfil profissional e carreira.

${ }^{9}$ Diversos outros estudos trazem reflexões relevantes sobre a origem da palavra gestão. Uma contribuição relevante e convergente com os propósitos dos estudos da administração política é a trazida por Paes de Paula (2016, p. 17-18) quando vai introduzir seu texto para tratar justamente das concepções inadequadas ou incompletas, como a gestão ou as práticas gerenciais têm sido tratadas na literatura de administração, principalmente (não se pode desconsiderar que diversos campos do conhecimento tomam a gestão e a a gerência como elementos complementares para suas reflexões e ações, a exemplo da pedagogia, da psicologia, das engenharias, da medicina, entre muitas outras).
} 
Administração política e políticas públicas: em busca de uma nova abordagem teórico-metodológica para a (re)interpretação das relações sociais de produção, circulação e distribuição
Reginaldo Souza Santos | Elizabeth Matos Ribeiro Mônica Matos Ribeiro | Fabiane Louise Bitencourt Pinto

ao macro, além de considerar que o processo de investigação não se restringe apenas a observar, descrever e explicar - é preciso propor e orientar.

Com base na afirmação do autor citado, cabe destacar o potencial da ciência da administração como campo científico que tem o compromisso, portanto, de refletir tanto em sua concepção como em sua ações empíricas as contradições ideológicas que marcam certa sociedade e/ou organização. Nesse sentido, ao ser compreendida como campo responsável por definir as formas de gestão das relações sociais de produção, circulação e distribuição, a administração política se qualifica para (re) afirmar que há outros caminhos possíveis de condução da vida social ou do que Santos, Ribeiro e Chagas (2009) denominam processo civilizatório ${ }^{10}$. É essencial, assim, que a administração, enquanto campo de reflexão e prática (práxis) humana, afaste-se do engajamento ideológico automático - manifesto nos princípios do imediatismo dos resultados econômicos - para se pronunciar, criticamente, em relação aos processos sociais estabelecidos de modo a propor alternativas para que parcela expressiva da sociedade/humanidade se liberte da necessidade de trabalhar até o último minuto de sua existência para ter a oportunidade de garantir uma materialidade mínima (sobrevivência) que garanta uma sobrevivência digna.

Ao resignificar os conceitos de gestão e gerência à luz da administração política, os estudiosos da área ressaltam que nem os referenciais teórico-metodológicos hoje disponíveis nem a empiria praticada no campo da administração conseguem responder às novas e desafiantes tarefas exigidas pela sociedade contemporânea. Essa constatação os leva a afirmar que é fundamental e urgente avançar no estudos teóricos e analíticos em administração para, assim, contribuir para transformar as práticas administrativas. Reforçam esse pressuposto ao afirmar que, se não houver investimentos consistentes e persistentes na espistemologia da ciência da administração, fatalmente não haverá avanços em sua empiria. O que significa concluir que se não houver mudanças nos conteúdos (na concepção, na gestão) e não se criar os instumentos para compreender melhor a realidade social e organizacional, certamente não haverá possibilidade de promover transformações nas formas de administrar, de conduzir as relações socais e organizacionais. Essa afirmação se fundamenta em avaliações sobre a maioria dos estudos administrativos disponíveis que revelam, segundo os autores, não terem o compromisso de oferecer um conhecimento crítico e contextualizado acerca da realidade; ao contrário disso, asseveram que a maioria dos estudos desenvolvidos no campo da administração são, em grande medida, casuísticos, formais e positivistas (SANTOS, RIBEIRO e CHAGAS, 2015).

Ao tomar por base teórica a (re)definição de um conceito-guia de gestão e gerência, a administração política tem a pretensão de distanciar-se das análises correntes, que não conseguem observar a gravidade do que está acontecendo nas relações sociais de produção, circulação e distribuição; ou, ao menos, sinalizar o que poderia mudar no rumo das políticas governamentais para o alcance de melhores resultados do esforço coletivo para assegurar o bem-estar da sociedade/humanidade. Ao contrário disso, observa-se que a maioria dos estudos sobre elaboração, implantação e/ou avaliação de políticas públicas tendem a concluir que as intervenções na realidade organizacional e/ou social estão corretas e legítimas, apenas carecendo de pequenas correções no campo da gestão ou da gerência - mesmo que não tenham clareza sobre o significado de tais conceitos e práticas administrativas.

Como ressaltam Santos, Ribeiro e Chagas (2015, p. 3):

[...] muitos dos erros e omissões das análises correntes ocorrem por conta do método utilizado (invariavelmente, baseado em estudos de caso) e da forma de abordagem (normalmente, trabalha-se mais sobre a concepção da intervenção e não sobre os resultados dela). Por exemplo, apesar do Sistema Único de Saúde [SUS] ter sido implantado há mais de duas décadas, os trabalhos acadêmicos são sempre circulares, com abordagens relativas à forma de implantação nesse ou naquele lugar; como se deu o processo de descentralização plena para o município tal ou qual; como foi formado o Conselho Municipal de Saúde; e assim por diante. Quando se investiga sobre os resultados da política pública, as abordagens são sempre no sentido de destacar que a implantação do sistema levou ao aumento expressivo no número de atendimentos; particularmente aqueles de média e alta complexidade. Quase

\footnotetext{
${ }^{10}$ Os autores estão convictos de que todo e qualquer conhecimento é fruto da ação do homo sapiens sobre a natureza, logo, os resultados desse conhecimento produzido devem ser direcionados para seu benefício - perdendo, assim, a tosca pretensão de neutralidade. A validade desse pressuposto fica reafirmada mais ainda quando se tratam das ciências humanas, nelas incluídas as aplicadas como a administração. Desse modo, torna-se risível a defesa de que a academia, para preservar sua autonomia investigativa, restrinja-se aos aspectos meramente científicos: observar, expor e explicar; os atos relativos a propor, orientar e dirigir estão carregados de valores, de subjetividades - estes não são atos próprios da ciência, são normativos e devem ficar, portanto, a cargo da política. No plano de trabalho da administração política, esses atos não são separáveis: pensar e agir fazem parte de um mesmo processo - separá-los tornase apenas um procedimento de elegância expositiva, nada mais do que isso.
} 
Administração política e políticas públicas: em busca de uma nova abordagem teórico-metodológica para a (re)interpretação das relações sociais de produção, circulação e distribuição
Reginaldo Souza Santos | Elizabeth Matos Ribeiro Mônica Matos Ribeiro | Fabiane Louise Bitencourt Pinto

nunca os trabalhos de investigação em Administração respondem como esse sistema está operando e em que condições; enfim, sobre a real efetividade de uma intervenção dessa natureza. Esse procedimento é estendido para outras áreas, a exemplo da educação, segurança pública, infraestrutura etc. Mais preocupante é que o governo e os órgãos de financiamento estão reféns dessa agenda elaborada pelas universidades, institutos de pesquisa e consultores - principalmente estes que parecem pautar os demais. Constrói-se, assim, uma rede de difícil dissolução porque o resultado de um trabalho sempre alimenta outro, com efeitos circulares, estabelecendo "verdades" pouco fundamentadas na realidade, mas consolidadas.

Os autores trazem para essa discussão, com propriedade, questões fundamentais que consideram ser de ordem ontológica, epistemológica e metodológica do campo das ciências administrativas. Para robustecer essa análise crítica, Santos, Ribeiro e Chagas (2015) trazem à luz os resultados de uma pesquisa recente realizada pelo Grupo de Estudos em Administração Política ${ }^{11}$, cujos dados revelam que os erros e vícios teóricos e metodológicos das análises recortadas da realidade organizacional e social (com ênfase nas abordagens tradicionais que orientam a análise e avaliação de políticas públicas) têm levado acadêmicos e gestores públicos a um juízo parcial dos processos e fenômenos administrativos, conduzindo-os a apresentar generalizações falseadas sobre a validade do conhecimento acerca da administração política e, em especial, da administração pública. Os autores ressaltam que, quanto mais se emprega esse expediente ou uma metodologia pragmatista (geralmente baseada em dados quantitativos e em análises focalizadas), portanto, mais restrita, mais a academia e os profissionais perdem a capacidade de cognição e de promover transformações substanciais na realidade, mantendo um discurso de transformação ideologizado, distante de promover mudanças substanciais nas relações sociais de produção, circulação e distribuição.

Pelas razões expostas, defendem ser imprescindível e urgente que a academia invista na produção de novas bases teórico-metodológicas comprometidas com a produção de estudos críticos e contextualizados sobre a realidade organizacional e social, de modo a possibilitar uma compreensão mais totalizante da gestão das relações sociais de produção, circulação e distribuição, especialmente as ações lideradas pelo Estado - concebidas e implementadas por meio de políticas públicas ações, cada vez mais, vocacionadas a atender, prioritariamente, os interesses privados do capital.

Com base nessa breve contextualização, defende-se neste artigo que a proposta teórico-metodológica da administração política contribui para que a administração possa se afastar da metodologia superficial e circunstancial predominante orientada pelos estudos de caso, para se aproximar de uma análise mais crítica e contextualizada da realidade, baseada, pois, em estudos censitários e buscando, assim, avançar em direção a uma compreensão mais ampla do funcionamento e dos resultados das ações do Estado e das relações deste com a sociedade. É esse, portanto, o esforço empreendido nas seções subsequentes.

\section{CONTRIBUIÇÕES DA ECONOMIA POLÍTICA PARA O CONCEITO DE ADMINISTRAÇÃO POLÍTICA}

Como tem sido destacado por diversos autores, o conceito de economia política como campo científico nasce no bojo do movimento de transformações das relações sociais de produção, circulação e distribuição que emergem no século XVIII, tendo Adam Smith como líder desse movimento intelectual e político - que definiu ser a economia política:

[...] um ramo dos conhecimentos do legislador e do homem de Estado, [a economia política] propõe-se a dois objetivos distintos: primeiro, o de propiciar ao povo um rendimento ou uma subsistência abundante, ou, mais adequadamente, de colocá-lo em condição de adquirir por si próprio esse rendimento ou essa subsistência abundante; o segundo objeto consiste em fornecer ao Estado ou à comunidade um rendimento suficiente para o serviço público: ela se propõe [a] enriquecer simultaneamente o povo e o soberano (SANTOS, RIBEIRO e CHAGAS, 2009, p. 922).

Ao assumir o conceito de economia política trazido por Adam Smith como referência central para a definição do conceito de administração política, Santos, Ribeiro e Chagas (2009) demarcam que os dois campos do conhecimento têm uma mesma origem, tomando como referência a dinâmica sócio-histórica da modernidade e contemporaneidade. Ao aceitar a definição da ciência econômica de Adam Smith como sendo o ramo dos conhecimentos do legislador e do homem de Estado, os autores

\footnotetext{
${ }^{11}$ Pesquisa com apoio do Conselho Nacional de Desenvolvimento Científico e Tecnológico (CNPq).
} 
Administração política e políticas públicas: em busca de uma nova abordagem teórico-metodológica para a (re)interpretação das relações sociais de produção, circulação e distribuição
Reginaldo Souza Santos | Elizabeth Matos Ribeiro Mônica Matos Ribeiro | Fabiane Louise Bitencourt Pinto

reconhecem, pois, que caberia ao direito, à economia e, também, à administração, como áreas líderes das ciências sociais aplicadas, a responsabilidade pela concepção mais geral (macro) da produção social (e respectivos processos de circulação e distribuição) - campo próprio da economia política -, da normatização e regulação desses processos - campo próprio do direito -, e da definição e orientação de toda e qualquer intencionalidade para dirigir e conduzir a concepção de uma dado padrão de produção social, assim como garantir os meios políticos e técnicos para viabilizar como essas relações sociais de produção, circulação e distribuição seriam materializadas - campo próprio da administração.

Em síntese, destaca-se que cabe à economia política assumir o papel de definir o que, por que e para que produzir, circular e distribuir certa concepção de materialidade social - definindo, pois, os meios para a provisão material individual e social, campo vinculado à essência filosófica e ética do sistema capitalista industrial. Enquanto cabe à administração política responder ao desafio, não menos importante, de conceber formas de gestar e gerenciar essa concepção socioeconômica. Assim, à administração política incumbe, portanto, conceber (gestar) e fazer (gerenciar/operacionalizar) os meios para garantir a condução das possibilidades (ideais, reais e potenciais) de produção, circulação/realização e distribuição, com vistas a elevar o nível de materialidade individual e social e garantir, desse modo, a sustentabilidade e reprodução do sistema socioeconômico.

Ao assumir o conceito de administração política como campo científico ${ }^{12}$ autônomo, os autores colocam as ciências administrativas em elevado patamar de contribuição acadêmica legitimado, portanto, por dois processos articulados: a) o ato de pensar (responsável pela dimensão filosófica da administração - a gestão); e b) o ato de agir (responsável pelas dimensões das práticas administrativas - a gerência) - possibilitando, dessa forma, o alcance de transformações das práticas sociais concretas. É, portanto, na articulação entre pensamento e ação administrativa que se encontra, pois, a essência do conceito de administração política e é onde se encontra a diferenciação (ainda que tênue) do conceito de economia política.

Diante do reconhecimento das complexas relações entre sociedade, Estado e mercado que fundam e orientam as sociedades capitalistas (modernas e contemporâneas), ganha relevância histórica os estudos das disciplinas economia política e administração política, ainda que as duas áreas tenham recebido pouca atenção por parte da academia tradicional e, também, dos governantes e homens de negócios, interessados apenas em garantir a maximização dos lucros e a socialização das perdas. A relevância desses dois campos do conhecimento se justifica devido à qualidade que assumem como espaços apropriados para fazer cumprir o desiderato natural da sociedade, que é garantir a liberdade de fazer e de dispor do que se faz. Com base nessa premissa, Santos, Ribeiro e Chagas (2009) defendem que, no contexto do capitalismo, há impossibilidade política e, sobretudo, técnica de fazer livremente e dispor igualmente do que se faz (da produção social).

Assim, a partir dessa compreensão os autores citados avançam na definição de um enquadramento teórico mais geral dos campos da economia política e da administração política. Vão ressaltar que a (re)interpretação da realidade social tanto da economia política como da administração política estão voltadas à e comprometidas com a construção de uma base material (produção social) que garanta à sociedade o bem-estar econômico e social que denominam finalidade social ${ }^{13}$. Afirmam, pois, que para que os indivíduos e a sociedade possam alcançar certa finalidade material, é preciso partir da compreensão das necessidades individuais, não contempladas nas relações de mercado - e que acabam por obstruir a conquista do bem-estar coletivo. Tais necessidades individuais vão compor, por sua vez, as necessidades coletivas, formadas a partir de uma compreensão de organização social hierarquizada e, portanto, excludente - como afirma Karl Marx, sustentada em uma sociedade de classes - e que vão conformar, pois, um conjunto de desejos que denominam necessidades coletivas, que vão originar um dado modo de concepção e execução de projeto de nação.

Assumindo o sentido e a validade do conceito de administração política como base cientifica da administração, pode-se deduzir que a concepção de determinado projeto de nação em certa sociedade revela a busca da finalidade última da vida social, materializada no alcance do bem-estar. O alcance da dimensão material, expressa pelas demandas coletivas (difusas), é dificultado pelas barreiras advindas da base técnica e organizativa que não cumprem seu papel, uma vez que seu desígnio é distinto dos interesses públicos, tendo em vista refletir interesses particularizados. Assim, ao reconhecer as necessidades

\footnotetext{
${ }^{12}$ Ao considerar esse desafio e defender as práticas e saberes administrativos como campo científico, Santos, Ribeiro e Chagas (2009, p. 921) avançam em uma revisão crítica sobre a concepção ideológica de ciência, especialmente a ciência moderna, destacando que "os filósofos da ciência (a filosofia da ciência) costumam fazer uma distinção entre o campo teórico (ciência) e o campo aplicado (ação/arte) como se um negasse o outro e não pudessem fazer parte de uma só totalidade para a compreensão plena de um mesmo (e só) sentido. Portanto, o campo puro (do que é e o que tende a ser) e o campo normativo (do que é e o que deve ser) estão interligados - a existência tem que ser compreensiva a partir do sentido (finalidade) da ação humana. Assim, a nossa compreensão da ciência engloba a parte que observa, que expõe e que explica (considerado o lado puro, científico) bem como a parte empírica, aplicada, normativa ou artística (que aconselha, que prescreve, que dirige). Só assim, o conhecimento (qualquer conhecimento) pode ser libertador do homem: desde relações hierarquizadas, produtoras de todo o sofrimento, até aquelas que levam à fadiga, à ânsia, à miséria, à fome”.

${ }^{13}$ Os autores utilizam como referência para a definição de bem-estar econômico o conceito de Arthur Pigou em seu livro Economics of welfare.
} 
Administração política e políticas públicas: em busca de uma nova abordagem teórico-metodológica para a (re)interpretação das relações sociais de produção, circulação e distribuição
Reginaldo Souza Santos | Elizabeth Matos Ribeiro Mônica Matos Ribeiro | Fabiane Louise Bitencourt Pinto

individuais que formam as necessidades coletivas e dão origem, portanto, ao projeto de nação, os autores se aproximam do campo próprio da economia política, que estuda as leis de funcionamento de determinado modo de produção, circulação e distribuição e que possibilita, em tese, o alcance da finalidade do bem-estar social.

Como destacou Adam Smith, o papel do Estado na condução do projeto de nação (que o autor denomina a riqueza das nações) seria, pois, levar a cabo as novas determinações da base política e material (econômica), definidas no âmbito da economia política. Ao ente estatal caberia viabilizar a finalidade do coletivo, de modo a assumir a gestão e execução (gerência) do projeto da nação, cuja finalidade última é alcançar o bem-estar coletivo. Desse modo, ao reconhecer o Estado como ente fundamental para a coordenação e regulação dos interesses individuais e coletivos, Santos, Ribeiro e Chagas (2009) dão à administração política a incumbência como gestora responsável por defender os interesses sociais mais amplos. O Estado atuaria como receptor das demandas/necessidades sociais coletivas e assumiria, assim, o papel de definidor das prioridades e temporalidades (teórica e administrativa) para a execução do projeto de nação.

Devido às funções e aos papéis que o Estado contemporâneo passou a assumir e à medida que as relações sociais de produção, circulação e distribuição se tornavam cada vez mais complexas, esse ente passou a ganhar status de executor e planejador de políticas públicas, constituindo o principal empreendedor individual do capitalismo e assumindo, desse modo, a condição de principal capitalista a comandar capitais (SANTOS e RIBEIRO, 1993; SANTOS, RIBEIRO, RIBEIRO et al., 2004). Assim, ao assumir o papel de gestor (responsável pela concepção dos padrões de administração política) e também de gerente (responsável pela execução desse macroprojeto - projeto de nação), o poder público passa a refletir a essência da definição de administração política.

Com essa breve síntese sobre as fronteiras e as aproximações entre a economia política e a administração política, buscou-se mostrar que ainda não foi escrito o capítulo sobre a concepção e realização de um padrão de gestão das relações sociais de produção, circulação e distribuição que responda aos novos e, cada vez mais, complexos desafios trazidos pela contemporaneidade. Essa conclusão se fundamenta no reconhecimento das subsequentes crises socioeconômicas que têm afligido os diversos modos de gestão do capitalismo nacional e, consequentemente, internacional, desde os anos 1970. Dentre tais crises, vale destacar duas: a) a crise do padrão socioeconômico, que tem afligido as principais economias desenvolvidas e emergentes; e b) a crise do padrão de administração política, que subjaz à crise econômica e avança em direção ao reconhecimento de uma crise mais profunda manifesta (implícita ou explicitamente) na incapacidade dos Estados nacionais e dos organismos multilaterais para superar tais dificuldades. A evidência mais forte desse termo pode ser observada no crescimento acelerado das assimetrias que marcam as relações sociais de produção, circulação e distribuição do capitalismo atual.

Desse modo, deve-se destacar as argumentações defendidas por Santos, Ribeiro e Chagas (2009), ao reconhecer a atualidade do conceito de economia política de Adam Smith, tendo em vista que permite reconhecer que, tanto no século XVIII como na contemporaneidade, há necessidade de garantir a provisão material (renda) para o Estado e para a sociedade, de modo a afiançar que o desenvolvimento pleno de determinado projeto de nação, fundado em princípios e objetivos sociais convergentes com a garantia do alcance do bem-estar social, não pode prescindir de meios subjetivos e concretos para sua administração.

Pode-se concluir essa seção anuindo com base na afirmação feita por Santos, Ribeiro e Chagas (2015) que todo e qualquer modo de gestão das relações sociais de produção, circulação e distribuição exige meios concretos para garantir sua administração. Em outras palavras, os autores ressaltam que falar de administração política é reconhecer que:

- Administrar é muito mais do que garantir a racionalidade dos processos de trabalho, com vistas ao aumento continuado da produtividade da economia dos negócios. Ao contrário disso, administrar implica, antes de tudo, conceber um padrão/modo de organização social que necessita construir e consolidar, científica e ideologicamente, um modelo/forma de hierarquia das relações sociais de produção, realização e distribuição.

\section{ADMINISTRAC̣̃̃o POLÍTICA: CONTRIBUIÇõES TEÓRICO-METODOLÓGICAS PARA A ANÁLISE E AVALIAÇÃO DE POLÍTICAS PÚBLICAS}

Tomar a administração política por base teórica e metodológica central para propor metodologias alternativas para avaliar políticas públicas exige fazer uma reflexão preliminar sobre as aproximações e os limites entre esse conceito e as abordagens mais convencionais que embasam as teorias racionais (positivistas) da administração pública. $O$ intuito é trazer alguns esclarecimentos essenciais para ajudar os interessados no tema (acadêmicos, profissionais e/ou cidadãos) a reduzir as confusões naturais sobre as duas abordagens. Essa confusão se deve ao fato da administração política reconhecer o papel central que o Estado passa a assumir no contexto da administração política do capitalismo contemporâneo, em âmbito internacional e 
Administração política e políticas públicas: em busca de uma nova abordagem teórico-metodológica para a (re)interpretação das relações sociais de produção, circulação e distribuição
Reginaldo Souza Santos | Elizabeth Matos Ribeiro Mônica Matos Ribeiro | Fabiane Louise Bitencourt Pinto

nacional. Como demonstra as evidências da história recente, as mudanças advindas do início dos anos 1930 até o final dos anos 1970 legitimam as conclusões trazidas por Santos e Ribeiro (1993), Santos, Ribeiro, Ribeiro et al. (2004), Santos (2004), Santos, Ribeiro e Chagas (2009) e Santos, Gomes, Santos et al. (2016) de que a economia capitalista passou a ser administrada pelo Estado - ainda que o objetivo central desse movimento tenha sido preservar os interesses liberais do mercado, como ratificam outros teóricos como Schumpeter (1964), Keynes (1983, 1992), Offe (1984), O'Connor (1977), Tragtenberg (1997), Bernardo (2000), Pedrão (2002).

Assim, esta seção apresenta, inicialmente, uma discussão preliminar sobre as diferenças e aproximações entre os conceitos de administração política e administração pública, buscando, com esse esforço, abrir um espaço de discussão acadêmico que integre as contribuições da epistemologia da ciência da administração como campo fundamental para complementar e avançar no entendimento dos princípios, valores, ideologias, técnicas e explicações (explícitas ou implícitas) que orientam a concepção e execução das relações sociais - das bases orientadoras do funcionamento da sociedade. E, em seguida, traz a síntese da proposição teórico-metodológica baseada na administração política para avaliar políticas públicas de forma mais abrangente e contextualizada, que consiga abarcar não apenas as perspectivas instrumentais ou funcionais que têm sido admitidas como exclusivas do campo da administração.

\section{ADMINISTRAÇÃo POLÍTICA E ADMINISTRAÇÃO PÚBLICA: DEFININDO AS FRONTEIRAS E INTER- RELAÇÕES ENTRE OS DOIS CAMPOS}

Embora os estudos sobre o papel e as ações do Estado não constituam novidade na história humana, tendo em vista que o pensamento grego clássico tem registros milenares sobre essa questão, as abordagens mais recentes sobre o tema das políticas públicas passaram a ganhar maior visibilidade e prioridade, a partir do século XX, momento em que as relações entre Estado e sociedade ganharam maior complexidade e passaram, então, a exigir investimentos no desenvolvimento de pesquisas e na formação profissional dos gestores públicos. Ao tomar como referência epistemológica e teórico-metodológica para análise e avaliação de políticas públicas a administração política, observa-se algumas aproximações com outras abordagens críticas sobre o tema, especialmente as contribuições críticas ou pós-positivistas. Essas correntes têm em comum com a administração política o reconhecimento de que as perspectivas estadocêntricas (definidas como políticas top down) não conseguem dar conta da complexidade das relações sociais reveladas pela multiplicidade atorial que as sociedades democráticas exigem. O que implica reconhecer que as ações do Estado no capitalismo, em especial, só podem ser compreendidas em um escopo mais amplo que envolve as demandas sociais, as possibilidades institucionais (legais e legítimas) do governo atender (por meio de planejamento e políticas públicas) e, por fim, a capacidade organizativa que tem a sociedade (por meio do mercado ou de outras formas de organização socioprodutiva) - o que representa, em síntese, a base teórica da administração política, como ilustra a Figura 1, e que diversos outros autores classificam como abordagens baseadas no conceito de ações do tipo bottom up, refletindo, pois, um papel mais ativo da sociedade na concepção e execução de políticas governamentais ou públicas. Sobre essas contribuições críticas sugere-se consultar os textos de Arretche (1998), Draibe (2001), Regonini (2001), Howllett e Ramesh (2003), Fischer (1995, 2016), Boullosa (2013), assim como os estudos que priorizam as abordagem da policy advocacy (BRELÁZ, 2007) e da policy network (FREY, 2000; BOULLOSA, 2013).

Vale destacar os avanços e as contribuições acerca da análise de políticas públicas que vai emergir, como destacado por Farah (2011), a partir das transformações que emergem da concepção e das responsabilidades que o Estado passou a assumir dos anos 1940 aos anos 1970, momento em que vai emergir o movimento das políticas de bem-estar social. Nesse contexto consagram-se, pois, os diretos sociais, que passam a incorporar o marco constitucional das sociedades desenvolvidas e que, de modo mais tímido, também será ampliado nas nações em desenvolvimento (ainda que com menor impulso e impacto). A expansão e consolidação de alguns direitos sociais cumpre duas funções centrais, conforme destacado por Offe (1984) e O'Connor (1977), tanto para dar conta das demandas sociais advindas dos movimentos político dos trabalhadores como para atender as necessidades de coordenação (administração) da economia de mercado.

Compreender ou (re)interpretar os fenomênos administrativos liderados pelo Estado à luz da administração política exige uma compreensão ampliada dos fundamentos que orientam as ações sócio-históricas da administração pública, especialmente desde o início dos anos 1930. Nesse contexto, as inter-relações sociedade-Estado-mercado (interesses públicos e interesses privados) assumem elevado grau de complexidade, na medida em que o Estado passa a ser o maior responsável pela 
Administração política e políticas públicas: em busca de uma nova abordagem teórico-metodológica para a (re)interpretação das relações sociais de produção, circulação e distribuição
Reginaldo Souza Santos | Elizabeth Matos Ribeiro Mônica Matos Ribeiro | Fabiane Louise Bitencourt Pinto

condução (administração) das relações sociais de produção, circulação e distribuição, com vistas a garantir a recuperação e a estabilidade do sistema econômico (SANTOS, 2004; SANTOS, RIBEIRO e CHAGAS, 2009). Desse modo, avaliar as políticas públicas - políticas estatais/governamentais - na perspectiva da administração política, implica (re)significar a dinâmica sócio-histórica do capitalismo contemporâneo (ver Figura 1), tendo por base as categorias de análise que envolvem a macrogestão, a mesogestão e a microgestão (PAES DE PAULA, 2016; SANTOS, 2017).

É, portanto, na base conceitual e epistemológica da administração política que se encontra a principal distinção com as abordagens da administração pública. Como definido por Santos (2004) e Santos, Ribeiro e Chagas (2009), o conceito de administração política é responsável por definir quais são os papéis e as funções que cada um dos entes envolvidos na concepção (gestão) e execução (gerência) de determinado projeto de nação ou projeto de sociedade (sociedade-Estado-mercado) assumirá. Se se toma como exemplo os padrões sócio-históricos que orientaram a administração política brasileira, do início dos anos 1930 até o final dos anos 1970, é possível identificar que o projeto de nação foi assumido pelo Estado, momento em que a administração pública ganha liderança e assume a responsabilidade pela concepção ( $g$ estão) e execução (gerência) do projeto nacional-desenvolvimentista que vai garantir a modernização econômica (BIELSCHOWSKY, 1988; SANTOS e RIBEIRO, 1993; SANTOS, RIBEIRO, RIBEIRO et al., 2004).

O que será ressaltado por Santos (2004) e Santos, Ribeiro e Chagas (2009) é que o papel central assumido pelo Estado brasileiro (pela administração pública), naquele contexto, foi definir e liderar o novo padrão de gestão das relações sociais de produção, circulação e distribuição, sustentado em um modelo de industrialização subordinado. Essa intepretação permite enxergar, portanto, que esse movimento macroeconômico integra o conjunto mais amplo dos interesses sociais, especialmente os caracterizados pelo mercado, enquanto se observa que as demandas sociais (representadas pelo conjunto mais amplo dos indivíduos) tenham ficado subordinadas ao alcance dos níveis ideais de desenvolvimento.

Pode-se deduzir, portanto, que o projeto de nação que emerge no Brasil entre o início dos anos 1930 até o final dos anos 1970, teve no Estado sua fonte central de poder e controle (condução) de todos os processos sociais, tecnológicos, econômicos, políticos e culturais. O que sugere concluir que esse novo modo de administração política determinou como o poder público deveria (re)estruturar-se para dar conta dos desafios impostos para a implantação e a consolidação da nova matriz socioeconômica fundada nos valores e princípios do capitalismo internacional. Desse modo, ao utilizar as categorias de análise centrais da administração política se observa, então, que as dimensões da gestão e da gerência que orientaram as relações sociais de produção, circulação e distribuição brasileira, evidenciam, claramente, a liderança absoluta do Estado na concepção e na execução desse projeto (SANTOS e RIBEIRO, 1993) ${ }^{14}$.

Para delimitar os objetivos deste artigo, mostra-se importante destacar que, enquanto o conceito clássico de administração pública ${ }^{15}$ representa, em linhas gerais, as regras para a regulação da ação do Estado e de seus agentes, estabelecida por lei, a abordagem trazida pela administração política inclui outros elementos centrais para o entendimento do que se define e caracteriza como bases de um dado projeto de nação ou projeto de sociedade. Nesse sentido, ao integrar o conceito de gestão pública ao de gestão dos interesses mais amplo da sociedade (administração política), amplia-se o escopo do entendimento do próprio conceito de políticas públicas, que não fica limitado estritamente ao conjunto de ações estatais (voltadas à organização e ao funcionamento do aparelho do Estado), mas abarca um conjunto mais amplo das interrelações naturais que

\footnotetext{
${ }^{14}$ Avançando na compreensão acerca dos processos e instrumentos de gestão e de gerência que se tornaram referências das transformações institucionais, organizacionais e administrativas que esse novo padrão de administração política brasileira vai engendrar, observa-se que o conjunto de reformas e processos de reestruturação do aparelho estatal está simbolizado, entre diversas inovações relevantes: na criação do Departamento Administrativo do Serviço Público (Dasp) em 1938, por Getúlio Vargas, e na reprodução dessa estrutura para as subunidades nacionais (através dos chamados "Daspinhos") e nas novidades originadas nos governos militares, especialmente por meio da promulgação da Lei n. 4.320/1964 e do Decreto-Lei n. 200/1967-que representam os suportes legais, políticos e técnicos básicos para que o Estado pudesse avançar nas atividades de planejamento governamental (SANTOS e RIBEIRO, 1993; SANTOS, RIBEIRO, RIBEIRO et al., 2004).

${ }^{15}$ Observa-se a existência de múltiplas definições para administração pública, desde as fundadas na doutrina jurídica clássica que o define como governo de um povo em um dado território, passando por acepções que o consideram aparato jurídico-político de uma nação, responsável por manter a coesão social (a ordem interna) do que é comum, alcançando outras noções mais amplas como as defendidas pelas escolas neoclássicas que admitem ser o Estado a instituição responsável por ofertar bens públicos, serviços de interesse comum, garantir direitos dos cidadãos, regular as ações da sociedade e do mercado e até estabilizar a economia. Merecem destaque, ainda, as abordagens críticas, especialmente a de origem marxista, que vão apresentar um contraponto às visões liberais do Estado, admitindo ser esta uma instituição de dominação dos interesses da burguesia, responsável por garantir os valores e princípios centrais do capitalismo (a propriedade privada e a liberdade individual), garantido, desse modo, as desigualdades essenciais para a preservação dos interesses individuais. Assim, ao se (re)interpretar a emergência do Estado capitalista, em contextos históricos diversos, se observará a defesa de diversos conceitos, o que implica que não é possível fechar a percepção de Estado em um único sentido, exigindo, igualmente, tecer relações com outros conceitos complementares como os de administração pública, economia política, administração política, dentre outros.
} 
Administração política e políticas públicas: em busca de uma nova abordagem teórico-metodológica para a (re)interpretação das relações sociais de produção, circulação e distribuição
Reginaldo Souza Santos | Elizabeth Matos Ribeiro Mônica Matos Ribeiro | Fabiane Louise Bitencourt Pinto

conformam os interesses conflitivos, materializados no que classificamos, aqui, como padrão de gestão das relações sociais de produção, circulçação e distribuição. Em síntese, é fundamental compreender que as ações estatais (políticas públicas) resultam de processos e dinâmicas sociais complexas que envolvem agentes situados em diversas e diferentes esferas de rerpesentação da sociedade, determinando, pois, o reconhecimento da existência de mecanismos formais e informais de acesso aos centros decisórios.

A partir dessa discussão preliminar sobre os conceitos de administração política e administração pública, as contribuições trazidas pelas bases teóricas e metodológicas da administração política para a avaliação de políticas públicas, tem como pressuposto central a compreensão das interrelações complexas estabelecidas, historicamente, entre sociedade-Estado-mercado, tomando por base as três dimensões centrais de análise definidas por Santos (2004) e Santos, Ribeiro e Chagas (2009), como mostra a Figura 1:

- A dimensão da sociedade: expressa através das necessidades individuais, materializadas nas demandas sociais (essa dimensão representa, portanto, as bases da economia política, como definido por Adam Smith);

- A dimensão do Estado: expressa por meio da capacidade de planejamento e de execução de políticas públicas (essa dimensão representa, portanto, as bases da administração política, não pela capacidade exclusiva de administrar o aparelho do Estado, mas principalmente por representar a liderança de um padrão mais geral em resposta às demandas da economia política); e

- A dimensão do mercado: expressa por meio da capacidade que os demais campos do conhecimento e de práticas sociais devem ter para implementar (executar) o projeto de nação e/ou o projeto de sociedade (essa dimensão representa, portanto, as bases técnicas da administração profissional, responsável pela engenharia dos processos).

Tomando por base essas três dimensões de análise que integram as categorias analíticas da gestão e gerência de determinado projeto de nação, defende-se que é possível pensar em metodologias avaliativas do desempenho das políticas governamentais (políticas públicas) com base em perspectivas teórico-metodológicas críticas. Com esse objetivo, a próxima subseção apresenta uma síntese propositiva de novos parâmetros teórico-metodológicos, com vistas a contribuir para um entendimento mais abrangente e contextualizado da performance dos fenômenos administrativos que orientam a condução dos interesses mais gerais da sociedade, que integram as inter-relações sociedade-Estado-mercado.

\section{UMA NOVA ABORDAGEM TEÓRICO-METODOLÓGICA PARA ANÁLISE E AVALIAÇÃO DE POLÍTICAS PÚBLICAS À LUZ DA TEORIA DA ADMINISTRAÇÃO POLÍTICA}

A gestão do capitalismo contemporaneo e brasileiro, em particular, estão passando por um momento muito delicado, não tanto pela gravidade dos problemas éticos, políticos, econômicos e sociais, mas muito mais pela pequena convicção do diagnóstico que tem sido realizado pelos acadêmicos, profissionais e gestores públicos sobre a origem da crise que tem sido imputada, desde os anos 1970, exclusivamente ao Estado (SANTOS, GOMES, SANTOS et al., 2016). Essas incertezas em relação à origem e causalidades reais dos problemas socioeconômicos, político-institucionais e administrativos tem produzido consequências dramáticas e ainda pouco dimensionadas em relação aos prognósticos ou encaminhamentos conservadores que tem optado por impor uma solução aparentemente mais simples pautada na defesa persistente de redução drástica do papel e funções do Estado, deixando ao mercado o papel natural de viabilizar as saídas possíveis. Essa abordagem reflete, pois, a preservação da ideologia liberal que historicamente tem revelado uma baixa capacidade (intencionalidade) de aprofundar o conhecimento acerca dos padrões de gestão atuais que orientam as relações sociais de produção, circulação e distribuição. Essa reduzida capacidade de compreensão crítica da realidade das atuais relações sociais tem a ver, portanto, com os métodos e a finalidade da maioria das pesquisas que têm sido desenvolvidas no campo da administração ${ }^{16}$, especialmente as dedicadas à análise de políticas públicas.

No campo da administração, os estudos voltados a um conhecimento mais profundo sobre a realidade têm-se revelado: a) casuísticos (estudos de casos), o que explica o fato de que a escolha do objeto estudado é pouco convincente; b) formalísticos, revelando que a base legal (institucional) é priorizada como principal fonte de inspiração para se avaliar os progressos e regressos, ou desempenho

\footnotetext{
${ }^{16}$ É relevante destacar que enquanto as chamadas ciências duras (exatas) trabalham diretamente com o fenômeno pesquisado, manipulando e experimentando a realidade (seja em laboratório ou fora desse ambiente); as ciências sociais (incluindo as aplicadas) têm trabalhado, preferencial e predominantemente, com dados secundários. Tal escolha de fontes de dados e informações caracteriza uma defasagem média quase nunca inferior a 5 anos e a escolha do instrumento de coleta não é adequada - tendo havido predominância dos métodos de pesquisa survey e similares. Além disso, os pesquisadores, na maioria dos casos, têm pouca ou nenhuma relação com o objeto de pesquisa.
} 
Administração política e políticas públicas: em busca de uma nova abordagem teórico-metodológica para a (re)interpretação das relações sociais de produção, circulação e distribuição
Reginaldo Souza Santos | Elizabeth Matos Ribeiro Mônica Matos Ribeiro | Fabiane Louise Bitencourt Pinto

dos fenômenos administrativos; e c) positivistas, reforçando sempre os elementos que legitimem alguma racionalidade que tende a orientar o caminho do mais favorável (reproduzindo, desse modo, os princípios que fundamentam o pensamento da economia e da administração científica neoclássica). O mais grave é que, ao priorizar essas metodologias - casuísticas, formalísticas e positivistas - os administradores clássicos ${ }^{17}$ concluem que as intervenções na realidade (as políticas públicas) estão sendo corretas e legítimas. Com esse diagnóstico frio e técnico, ousam apresentar prognósticos tão simplistas quanto as análises pretéritas, sugerindo, em alguns casos, a necessidade de pequenas correções (na margem) no campo da gestão e da gerência (SANTOS e GOMES, 2013).

As consequências mais graves da predominância das abordagens teórico-metodológicas de perfil mais racionalista é que as questões centrais que o atual padrão de administração política do capitalismo contemporâneo e brasileiro, em particular, está enfrentando ficam praticamente excluídas dessas análises mais superficiais. Uma primeira evidência dessa incoerência ou inconsistência teórico-metodológica é que, na maioria dos estudos sobre políticas públicas, há predominância de priorizar como objeto de estudo as metas (com ênfase nos aspectos orçamentários e financeiros), em detrimento de proceder a uma avaliação do alcance efetivo da finalidade das políticas públicas. O que revela falta de prioridade em eleger os resultados (preservação dos princípios clássicos de custo-beneficio) em detrimento do conteúdo e dos propósitos das ações públicas, especialmente quando estas são lideradas pelo Estado. Tal opção convervadora e limitada de (re)interpretar a realidade social e organizacional revela, portanto, a baixa cognição que os administradores (acadêmicos e profissionais/gestores públicos) apresentam para compreender a realidade (social e organizacional) e a pouca utilidade que os produtos desses estudos/ pesquisadas têm, particularmente como retroalimentadores e (re)orientadores das ações governamentais e da sociedade (no papel de beneficiário direto e no exercício pleno de sua responsabilidade de fazer controle social).

Outro aspecto importante que a proposta teórico-metodológica aqui apresentada ressalta é a não revelação das atuais pesquisas com preocupações de questionar o senso comum. Um exemplo que pode ser destacado é a ausência de senso crítico que esses textos revelam ao apresentar conclusões que, geralmente, destacam que a falta de recursos financeiros explica uma parte relevante do fracasso das políticas públicas. Contudo, ao difundir apressadamente essa afirmação, caberia perguntar:

- Essa conclusão reflete um pressuposto ou uma constatação fundada em dados empíricos concretos?

Mesmo que em alguns casos pontuais se observe a necessidade de aumento de gastos, não seria importante utilizar outras suposições relacionadas, como, por exemplo:

- Avaliar o impacto do índice de absenteísmo dos funcionários públicos na quantidade, qualidade e alcance de determinada política pública ${ }^{18}$ ?

Com essa análise crítica preliminar, o que se almeja destacar, antes de apresentar a proposta teórico-metodológica aqui anunciada, é o fato de que quando se admite, sem maiores questionamentos, como variável determinante a falta de recursos públicos, sem que esse diagnóstico reflita apenas um dado frio - revelando-se mais como resultado de uma crença ou doutrina do que como fruto de uma reflexão científica ${ }^{19}$ (SOUZA SANTOS, 1999) - o esforço acadêmico perde sentido e finalidade, pois acaba assumindo o papel de legitimar interesses ou ideologias vazias de sentido como prática social e/ou organizacional.

Nesse sentido, ao tomar como base teórico-metodológica a administração política a intenção é trazer ao debate uma nova metodologia mais compreensiva de nossa realidade, capaz de oferecer elementos conceituais, factuais e parâmetros técnicos que contribuam para que o Estado e a sociedade brasileira possam melhorar a concepção (gestão) e execução (gerência) das políticas públicas. Com essa ambição, espera-se colocar a ciência da administração em condições de estabelecer um diálogo consistente com outros campos do conhecimento, especialmente a economia (neoclássica) que tem dominado o espaço de decisão e condução dos interesses predominantes que fundam e guiam, até os dias atuais, os padrões de gestão das relações sociais de produção, circulação e distribuição das sociedades contemporânea e brasileira, em particular, como já destacado.

Assim, avaliar as políticas públicas à luz da administração política significa considerar categorias de análise centrais a capacidade de gestão e a capacidade de gerência, integrando as dimensões política e instrumental/técnica como elementos indissodiáveis do fenômeno administrativo. Como já ressaltado ao longo do texto, o conceito de administração política considera a estreita correlação com o campo de pensamento e atuação prática da economia política, o que possibilita tratar nosso objeto de pesquisa - as políticas públicas/estatais - utilizando categorias próprias da ciência econômica e integrando a estas a

\footnotetext{
${ }^{17}$ Que integram a escola ortodoxa de administração, como categorizam Serva (2013), Paes de Paula (2016), Santos (2017), entre outros estudiosos críticos vinculados aos estudos organizacionais e aos estudos críticos da administração.

${ }^{18}$ Sobre esse tema ver Santos, Barreto, Ribeiro et al. (2009).

${ }^{19} \mathrm{O}$ conceito de ciência, especialmente a aplicada ao campo da administração, está sendo compreendido em sua dimensão crítica, comprometida, não apenas, como observar, expor e explicar, mas, também como aconselhar, prescrever e dirigir, com vistas a proporcionar transformações na qualidade de vida social e organizacional (SANTOS, RIBEIRO e CHAGAS, 2009, p. 22-23).
} 
Administração política e políticas públicas: em busca de uma nova abordagem teórico-metodológica para a (re)interpretação das relações sociais de produção, circulação e distribuição
Reginaldo Souza Santos | Elizabeth Matos Ribeiro Mônica Matos Ribeiro | Fabiane Louise Bitencourt Pinto

finalidade da ciência da administração, buscando avaliar o desempenho da demanda (real e potencial) e oferta (real e potencial) de bens e serviços públicos, tendo como resultado final (ideal) dessa equação a eliminação de insatisfação social (que abarca tanto o atendimento das necessidades básicas dos indivíduos, como os esforços necessários para a produção do que Smith (1986) traduziu como a riqueza das nações.

Um dos aspectos centrais da proposta teórico-metodológica aqui defendida é abandonar o uso corrente da pesquisa secundária e os métodos de amostragem para adotar, definitivamente, as técnicas censitárias como recurso de observação privilegiado. Defende-se que esse percurso possibilita o administrador, especialmente o que tem vocação e compromisso acadêmico, a integrar em sua análise as dimensões da gestão e da gerência, considerando, de modo integrado, tanto os níveis subjetivos que envolvem o âmbito da concepção (de difícil apreensão, visto que grande parte não se explicita de forma visível, é preciso buscar essa informação) como abarcam os níveis mais empíricos que expressam o âmbito da execução das políticas públicas campo próprio da administração profissional ${ }^{20}$.

Em síntese, a base central que orienta a metodologia proposta se fundamenta no método censitário por considerar que esse caminho pode auxiliar a melhor compreensão dos fenômenos gestorial e gerencial, se comparado à técnica amostral. Essa defesa do método qualitativo e censitário se justifica, portanto, em razão do elevado grau de subjetividade que a avaliação de saberes e práticas administrativas (CORREA e JURADO, 2003) exigem. Essa escolha ganha maior relevo quando se está buscando avaliar as políticas públicas por sua finalidade e efetividade e não apenas perseguir, desesperadamente, os indicadores de produtividade dos processos administrativos ${ }^{21}$.

Assim, ao invés de privilegiar a posse de referenciais cujos resultados amostrais servissem apenas de indicadores para a validação das categorias analíticas prévia e cuidadosamente escolhidas, optou-se por uma análise/avaliação mais conteudista e que só pode ser realizada em sua totalidade por meio do censo. Com essa escolha, será possível obter melhor compreensão das múltiplas causalidades que explicam as razões que têm levado o Estado a ofertar serviços e bens públicos insuficientes e/ou de baixa qualidade.

Definido o escopo teórico e metodológico mais amplo que deverá orientar a pesquisa avaliativa de políticas públicas, devem ser apresentados os instrumentos que proporcionam suporte ao estudo. Como ponto de partida, sugere-se definir alguns indicadores quantitativos que sirvam de base inicial para avaliar o nível de demanda social - que podem ser os parâmetros estabelecidos pelas agências multilaterais e legitimadas pelos governos, de modo a estabelecer as bases para o desenho preliminar da equação e das variáveis de análise que ajudarão a avaliar os aspectos qualitativos da gestão e da gerência das políticas públicas selecionadas.

Como exercício acadêmico preliminar, com vistas a conferir forma ao desenho metodológico aqui proposto, expresso esquematicamente no Quadro 1, foram tomadas como referências as seguintes dimensões de análise:

1. avaliar as condições, efetiva e potencial, de atendimento das políticas públicas (selecionadas);

2. avaliar a capacidade, real e potencial, da oferta de bens e serviços públicos disponibilizados pelo poder público (integrando no caso da organização do Estado brasileiro, a União e as subunidades nacionais);

3. avaliar a capacidade, real e potencial, do cumprimento das horas de trabalho contratadas.

Com essa proposta se almeja avaliar, inicialmente, a capacidade da produção de bens e serviços instalada que, para dar conta do que a sociedade espera (visto que essa demanda deve refletir o conjunto de necessidades individuais materializadas em demanda social) deve funcionar em sua plenitude. Ao medir a capacidade institucional disponibilizada à sociedade, é possível, pois, levantar indicadores que neguem ou confirmem os discursos, majoritarimente demagógicos, que têm sido afirmados por representantes dos governos, gestores e burocratas e acadêmicos engajados de que o Estado atual não tem mais capacidade de atender as crescentes demandas sociais.

Com base nessa compreensão ampliada da capacidade instalada, é fundamental que o pesquisador identifique qual seu objeto de estudo privilegiado. E, em se tratando de avaliação de políticas públicas tendo por referência o olhar da administração

\footnotetext{
${ }^{20}$ É importante esclarecer que não há uma rejeição das contribuições relevantes que os indicadores e índices quantitativos podem e têm trazido para os estudos dessa natureza. Avesso a essa posição radical e excludente o que se propõe é utilizar criteriosamente alguns dos dados e indicadores existentes (desde que se tenha atenção quanto às metodologias mais ortodoxas ou superficiais que podem embasar tais estudos) como ponto de partida, mas ampliando seu escopo para dar conta de uma visão mais alargada do que se entende por administração (ultrapassando, assim, a percepção tecnicista).

${ }^{21} \mathrm{O}$ que se deseja não é apenas medir a qualidade da saúde ofertada à população tomando por base a relação simples expressa no indicador médico/paciente; mas, sobretudo, pelo índice de cura (pela capacidade de acertividade e efetividade) que essa ação pública é ou pode ser capaz de produzir, seja a partir da primeira consulta ao médico de plantão ou no atendimento hospitalar de rotina. De igual modo, a qualidade da política de educação, ao invés de ser avaliada apenas pelos indicadores de matrícula (módulos), ou pela relação professor/aluno, pelo índice de evasão escolar, deveria ser compreendida no contexto de cada etapa escolar do estudante para se definir quais saberes ou competências básicas ou qual é a capacidade cognitiva que o aluno deve ter para ser capaz não apenas de reproduzir conhecimentos, mas ser capaz de ler, de (re)significar e de atuar no mundo ao qual esteja circunstanciado - utilizando como inspiração o sentido e o significado da pedagogia freireana (FREIRE, 1987).
} 
política, é essencial considerar, em primeiro lugar, o contexto no qual essas ações estão ocorrendo para evitar, assim, a tentação de replicar metodologias forâneas (geralmente pré-fabricadas/concebidas por técnicos ou consultores pagos para fazer tal serviço para atender, geralmente, a interesses escusos ou obscuros), privilegiando sempre que possível se inspirar nas filosofias populares/simples, a exemplo da pedagogia do oprimido, de Freire (1987), entre muitas outras abordagens sociointeracionistas e inclusivas. $O$ passo seguinte é selecionar as áreas que se avalie mais carentes de estudos dessa natureza crítica e compreensiva. Podem ser sugeridas algumas que têm ganhado mais evidências nos tempos atuais, como as políticas de saúde, de educação, de segurança, de imigração, de cultura, de meio ambiente, entre muitas outras reveladoras do aprofundamento das assimetrias que a gestão do capitalismo contemporâneo e brasileiro, em particular, tem produzido.

\section{Quadro 1}

Equação/método para avaliar capacidade de gestão e de gerência em políticas públicas

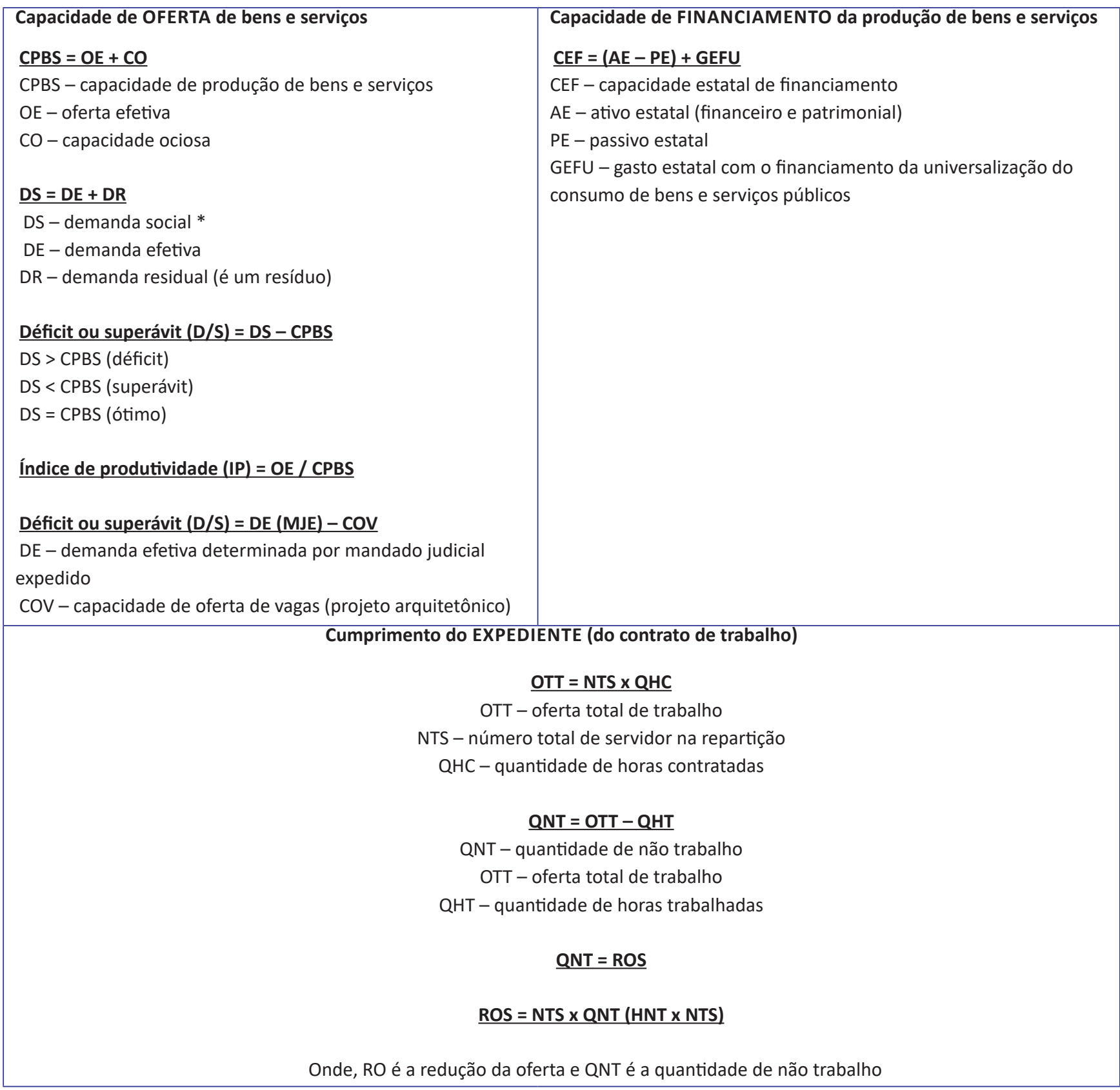

Fonte: Santos, Ribeiro e Chagas (2015, p. 27). 
Administração política e políticas públicas: em busca de uma nova abordagem teórico-metodológica para a (re)interpretação das relações sociais de produção, circulação e distribuição
Reginaldo Souza Santos | Elizabeth Matos Ribeiro Mônica Matos Ribeiro | Fabiane Louise Bitencourt Pinto

Deve ser ressaltado que essa metodologia já foi testada em pesquisa aplicada à realidade das políticas de saúde, educação e segurança pública junto ao municipio de Itabuna (BA) e existem dois outros estudos em desenvolvimento que estão aplicando essa metodologia junto aos municípios de Vitória da Conquista (BA) e Arapiraca (AL).

Oxalá esse interesse possa ser ampliado e esse expediente possa ser replicado por outros interessados, assim como aqueles que tenham a pretensão de aprofundar a discussão, de modo a contribuir para o avanço de novas abordagens teórico-metodológicas semelhantes. Sem dúvida, essa possibilidade agregaria valor aos esforços que vem sendo empreendidos por diversos grupos de pesquisa que já militam na seara da espistemologia crítica dos estudos organizacionais, dos estudos críticos em administração, dos estudos em administração política, dos estudos sobre o pensamento da administração brasileira, enfim, todos os que, como destacado por Serva (2013, p. 502, grifo do autor), "acreditam e trabalham em prol da construção de uma ciência com consciência também no campo da administração". Esperamos que este artigo constitua inspiração nesse sentido.

\section{CONSIDERAÇÕES FINAIS}

Pelos argumentos expostos neste ensaio, que tomou por base fundamental as proposições epistemológicas críticas em administração com ênfase especial às contribuições da teoria da administração política, é possível tecer algumas considerações finais que têm por finalidade não encerrar esse diálogo profícuo, que necessita ser aprofundado, mas pontuar alguns aspectos que podem servir como uma agenda para novas discussões sobre o tema.

Destacamos os seguintes temas considerados preliminarmente mais relevantes que carecem de reflexões proativas e propositivas por parte dos estudiosos da ciência da administração:

- É essencial superar, definitivamente, a compreensão equivocada de que há uma separação ou apenas uma complementariedade entre administração e política, como tem sido comumente discutido na literatura corrente sobre o tema, especialmente os autores que tratam da abordagem da administração pública. Ao analisar as contribuições da administração política e de outros estudos críticos em administração e das abordagens dos estudos organizacionais se encontram argumentos que comprovam essa impossibilidade, na medida em que consideram que se trata de duas dimensões entrelaçadas e integradas historicamente, desde os mais remotos processos de organização social até a atualidade. Admitir, pois, que há uma administração política é um passo para reconhecer algo que parece uma obviedade: que as relações sociais são administradas, são conduzidas. O que implica considerar que os vários modos de administrar as organizações sociais (pública ou privada) integram, obrigatoriamente as dimensões subjetivas (políticas) e também acolhem as dimensões técnicos/tecnológicos, como reflexo, pois, das possibilidades (subjetivas, simbólicas e concretas) de materializar determinado projeto de nação e/ou um projeto de sociedade;

- Ao considerar que há uma administração política que orientam as relações sociais de produção, circulação e distribuição, o próximo e mais desafiador passo é investir na construção de bases teórico-epistemológicas e metodológicas que auxiliem a ciência da administração a exercitar sua capacidade de produzir conhecimento próprio e, com esse potencial interpretativo, avançar nos elementos que possibilitem administrar melhor os interesses coletivos e individuais; e

- Por fim, merece destacar a validade das contribuições deste ensaio em relação às bases teórico-metodológicas para analisar e avaliar políticas públicas, considerando que amplia as possibilidades de observar e orientar as ações estatais em uma perspectiva mais ampliada; isto é, como produto e produtora de um dado padrão de gestão das relações sociais de produção, circulação e distribuição (envolvendo nesse arcabouço analítico as dimensões próprias da administração: a gestão e a gerência).

Como ressaltado por Santos (2017, p. 226), esse esforço possibilitará ao campo da ciência da administração

[...] contemplar as diversas formas de gestão das relações sociais, independente do sistema econômico de produção ou do seu tempo histórico. Só assim acreditamos que seja possível desenvolver um conhecimento [sobre os fenômenos administrativos] que integra e engloba e não que exclui e fragmenta, evitando, com isso, uma visão desatualizada, doutrinária e acrítica da administração.

Esperamos que as reflexões destacadas neste ensaio contribuam para que os estudiosos (pesquisadores aplicados ou aqueles que têm maior vocação para a filosofia) e os profissionais possam se apropriar das discussões e provocações trazidas aqui que tiveram por finalidade última ressaltar que o campo da administração influencia e é influenciado pelas correlações de forças ideológicas/teóricas, políticas, sociais, econômicas e culturais que fundamentam as relações sociais (em âmbito internacional, nacional e local) e que repercute (explícita ou implicitamente) nas práticas de gestão e nas práticas gerenciais. 
Administração política e políticas públicas: em busca de uma nova abordagem teórico-metodológica para a (re)interpretação das relações sociais de produção, circulação e distribuição
Reginaldo Souza Santos | Elizabeth Matos Ribeiro Mônica Matos Ribeiro | Fabiane Louise Bitencourt Pinto

\section{REFERÊNCIAS}

AKTOUF, O. Administração e teorias das organizações contemporâneas: rumo a um humanismo radical? Organizações \& Sociedade, v. 21, n. 8, p. 13-33, 2001.

AKTOUF, O. Pós-globalização, administração e racionalidade econômica: a síndrome do avestruz. São Paulo: Atlas, 2004.

ALVESSSON, M.; WILLMOTT, H. Critical management studies. London: Sage, 1992.

ARRETCHE, M. T. S. Tendências no estudo sobre avaliação. In: RICO, E. M. (Org.). Avaliação de políticas sociais: uma questão em debate. São Paulo: Cortez, 1998. p. 29-39.

AZEVEDO, A.; GRAVE, P. S. Prolegômenos a toda a administrologia possível: administração - o que é isso? Organizações \& Sociedade, n. 71, p. 695-712, 2014.

BERNARDO, J. Transnacionalização do capital e fragmentação dos trabalhadores. São Paulo: Boitempo, 2000.

BIELSCHOWSKY, R. Pensamento econômico brasileiro: o ciclo ideológico do desenvolvimento. Rio de Janeiro: Ipea/INPES, 1988.

BOULLOSA, R. F. Mirando ao revés nas políticas públicas: notas sobre um percurso de pesquisa. Revista Pensamento \& Realidade, v. 28, n. 3, p. 67-84, 2013.

BRELÁZ, G. Advocacy das organizações da sociedade civil: principais descobertas de um estudo comparativo entre Brasil e Estados Unidos. In: ENCONTRO DA ASSOCIAÇÃO NACIONAL DOS PROGRAMAS DE PÓS-GRADUAÇÃO EM ADMINISTRAÇÃO, 31., 2007, Rio de Janeiro. Anais... Rio de Janeiro: AnPAD, 2007. p. 1-16.

CORREA, P.; JURADO, J. Fundamentos del saber administrativo. Cuadernos de Difusion, v. 8, n. 15, p. 82-100, 2003.

CUNHA, M. P. Ciência organizacional: passado, presente, futuro ou uma viagem dos clássicos aos pós-modernos. In: CUNHA, M. P. Teoria organizacional: perspectivas e prospectivas. Lisboa: Dom Quixote, 2000. p. 47-65.

DAVEL, E.; ALCADIPANI, R. Estudos críticos em administração: a produção científica brasileira dos anos 1990. Revista de Administração de Empresas, v. 43, n. 4, p. 72-85, 2003.

DIMOCK, M. E. The study of administration. American Political Review, v. 31, n. 1, p. 28-40, 1937.

DIMOCK, M. E. Filosofia da administração. Rio de Janeiro: Fundo Cultural, 1968.

DRAIBE, S. M. Avaliação de implementação: esboço de uma metodologia de trabalho em políticas públicas. In: BARREIRA, M. C. R. N.; CARVALHO, M. C. B. (Org.). Tendências e perspectivas na avaliação de políticas e programas sociais. São Paulo: PUC-SP, 2001. p. 13-42.

FARAH, M. Administração pública e políticas públicas. Revista de Administração Pública, v. 45, n. 3, p. 813-836, 2011.

FAYOL, H. Administration industrielle et générale: prévoyance, organisation, commandement, coordination, controle. Paris: $\mathrm{H}$. Dunod et E. Pinat, 1916.
FILIPPIN, M. A natureza política da administração. 153 f. Tese (Doutorado em Administração) - Universidade Federal do Rio Grande do Sul, Porto Alegre, 2017.

FISCHER, F. Evaluating public policy. Chicago: Nelson-Hall, 1995.

FISCHER, F. Para além do empirismo: policy inquiry na perspectiva pós-positivista. Revista NAU Social, v. 7, n. 12, p. 163-180, 2016.

FOURNIER, V.; GREY, C. At the critical moment: conditions and prospects for critical managment studies. Human Relations, v. 53, n. 1, p. 7-32, 2000.

FRANÇA FILHO, G. C. Para um olhar epistemológico da administração: problematizando o seu objeto. In: SANTOS, R. S. (Org.). A administração política como campo do conhecimento. São Paulo: Mandacaru, 2004. p. 19-143.

FREIRE, P. Pedagogia do oprimido. 17. ed. Rio de Janeiro: Paz e Terra, 1987.

FREY, K. Políticas públicas: um debate conceitual e reflexões referentes à prática da análise de políticas públicas no Brasil. Planejamento e Políticas Públicas, Brasília, n. 21, p. 211-259, 2000.

GOODNOW, F. J. Politics and administration: a study in government. 3. ed. New Brunswick, NJ: Transaction, 2003.

GUERREIRO RAMOS, A. A nova ciência das organizações: uma reconceituação da riqueza das nações. 2. ed. Rio de Janeiro: Ed. FGV, 1989.

GUIMARÃES, M. C. L. et. al. Avaliação da capacidade de gestão de organizações sociais: uma proposta metodológica em desenvolvimento. Cadernos de Saúde Pública, v. 20, n. 6, p. 1642-1650, 2004.

HOWLLETT, M.; RAMESH, M. Studying public policy. London: Oxford, 2003.

JAPIASSU, H. Introdução ao pensamento epistemológico. 6. ed. Rio de Janeiro: Francisco Alves, 1992.

KEYNES, J. M. O fim do laissez-faire (1926). In: SZMRECSÁNYI, T. (Org.). Keynes (economia). São Paulo: Ática, 1983. p. 106-126.

KEYNES, J. M. Teoria geral do emprego, do juro e da moeda. São Paulo: Atlas, 1992.

MATUS, C. Política, planejamento e governo. Brasília (DF): Ipea, 1993. $2 \mathrm{t}$

MISOCZKY, M. C.; ANDRADE, J. A. Uma crítica à crítica domesticada nos estudos organizacionais. Revista de Administração Contemporânea, v. 9, n. 1, p. 215-233, 2005.

O'CONNOR, J. USA: a crise fiscal do Estado capitalista. Rio de Janeiro: Paz e Terra, 1977.

OFFE, C. Problemas estruturais do estado capitalista. Rio de Janeiro: Tempo Brasileiro, 1984.

PAES DE PAULA, A. P. Em busca de uma ressignificação para o imaginário gerencial: os desafios da criação e da dialogicidade. Revista de Administração Mackenzie, v. 17, n. 2, p. 18-41, 2016.

PEDRÃO, F. O planejamento socialmente necessário. Análise e Dados, v. 12, n. 2, p. 23-26, 2002. 
Administração política e políticas públicas: em busca de uma nova abordagem teórico-metodológica para a (re)interpretação das relações sociais de produção, circulação e distribuição
Reginaldo Souza Santos | Elizabeth Matos Ribeiro Mônica Matos Ribeiro | Fabiane Louise Bitencourt Pinto
REED, M. Teorização organizacional: um campo historicamente contestado. In: CALDAS, M.; FACHIN, R.; FISCHER, T. (Ed.). Handbook dos estudos organizacionais: modelos de análises e novas questões em estudos organizacionais. São Paulo: Atlas, 1999. v. 1, p. 61-98.

REGONINI, G. L'analisi delle politiche pubbliche. In: FREDDI, G (Org.). Scienza dell'amminsitrazione e politiche pubbliche. La Nuova Italia, p. 313-49, 2001.

RIBEIRO, J. U. Administração e política. Organizações \& Sociedade, v. 13, n. 38, p. 162-194, 2006.

SANTOS, E. L. O campo científico da administração: uma análise a partir do círculo das matrizes teóricas. Cadernos EBAPE.BR, v. 15, n. 2, p. 209-228, 2017.

SANTOS, R. S. A administração política como campo do conhecimento. São Paulo/Salvador: Hucitec/Mandacaru, 2004.

SANTOS, R. S.; GOMES, F. G. Estranhos acontecimentos e a pesquisa em administração. Revista Brasileira de Administração Política, v. 6, n. 1, p. 5-12, 2013.

SANTOS, R. S.; RIBEIRO, E. M. A administração política brasileira. Revista de Administração Pública, v. 27, n. 4, p. 102-135, 1993.

SANTOS, R. S.; RIBEIRO, E. M.; CHAGAS, T. Bases teórico-metodológicas da administração política. Revista de Administração Pública, v. 43, n. 4, p. 919-941, 2009.

SANTOS, R. S.; RIBEIRO, E. M.; CHAGAS, T. Empiria e construção de novos parâmetros teórico-metodológicos para avaliação da administração política brasileira: análise dos resultados da pesquisa realizada no município de Itabuna-BA, nas áreas da saúde, da educação e da segurança pública. Salvador: UFBA/CNPq, 2015. [Não publicado].

SANTOS, R. S. et al. Reestruturação produtiva do Estado na perspectiva neoliberal. Revista de Administração Pública, v. 38, n. 1, p. 7-32, 2004.

SANTOS, R. S. et al. O expediente: a dimensão esquecida da administração política. Organizações \& Sociedade, v. 16, n. 49, p. 373387, 2009.

SANTOS, R. S. et al. A crise, o Estado e os equívocos da administração política do capitalismo contemporâneo. Cadernos EBAPE.BR, v. 14, n. 4, p. 1011-1034, 2016.
SCHUMPETER, J. História da análise econômica. Rio de Janeiro: Fundo de Cultura, 1964. 3 v.

SERVA, M. Epistemologia e sociologia da ciência da administração. Cadernos EBAPE.BR, v. 11, n. 4, p. 500-503, 2013.

SMITH, A. A riqueza das nações: investigação sobre a natureza e suas causas. São Paulo: Abril Cultural, 1986.

SOUZA SANTOS, B. Porque é tão difícil construir uma teoria crítica? Revista Crítica de Ciências Sociais, v. 54, p. 197-215, 1999.

SOUZA SANTOS, B. Um discurso sobre as ciências. São Paulo: Cortês, 2010.

TAYLOR, F. W. Princípios de administração científica. 2. ed. São Paulo: Atlas, 1976.

TRAGTENBERG, M. A teoria geral da administração é uma ideologia? Revista de Administração de Empresas, v. 11, n. 4, p. 7-21, 1971.

TRAGTENBERG, M. Administração, poder e ideologia. São Paulo: Cortez, 1989.

TRAGTENBERG, M. Burocracia e ideologia. São Paulo: Ática, 1997.

VIZEU, F. Potencialidades da análise histórica nos estudos organizacionais brasileiros. Revista de Administração de Empresas, v. 50, n. 1, p. 37-47, 2010a.

VIZEU, F. (Re)contando a velha história: reflexões sobre a gênese do management. Revista de Administração Contemporânea, v. 14, n. 5 , p. $780-797,2010 b$.

WALDO, D. The administrative state: a study of the political theory of American public administration. New York: Ronald Press, 1948.

WEBER, M. Ensaios de sociologia. 3. ed. Rio de Janeiro: Zahar, 1974.

WEBER, M. Parlamento e governo na Alemanha reordenada: crítica política do funcionalismo e da natureza dos partidos. Petrópolis, RJ: Vozes, 1993.

WEBER, M. Economia e sociedade. Brasília (DF): Ed. UnB, 2000.

WEBER, M. Ciência e política: duas vocações. 18. ed. São Paulo: Cultrix, 2011.

WILSON, W. O estudo da administração. Revista do Serviço Público, v. 56, n. 3, p. 349-366, 2005. 
Pós-Doutorado pelo Instituto Superior de Economia e Gestão (ISEG) da Universidade Técnica de Lisboa (UTL); Doutor em Economia pela Universidade Estadual de Campinas (UNICAMP); Professor titular do Núcleo de Pós-Graduação em Administração da UFBA. E-mail: rsouza@ufba.br

\section{Elizabeth Matos Ribeiro}

Doutora em Ciências Políticas e da Administração pela Universidade Santiago de Compostela - Espanha (USC-ES); Professora Adjunta I do Departamento de Finanças e Políticas Públicas da Escola de Administração da Universidade Federal da Bahia (EAUFBA). E-mail: ematos@ufba.br

Mônica Matos Ribeiro

Doutoranda em Administração pela Universidade Federal da Bahia; Mestre em Administração pela Universidade Federal da Bahia; Professora Auxiliar do Departamento de Ciência Humanas, Campus V, Colegiado de Administração da Universidade do Estado da Bahia (UNEB). E-mail: monica.matos@yahoo.com.br

Fabiane Louise Bitencourt Pinto

Doutoranda em Administração pela Universidade Federal de Minas Gerais; Mestre em Administração pela Universidade Federal da Bahia; Especialista em Políticas Públicas e Gestão Governamental do Estado da Bahia, lotada na Secretaria de Administração do Estado da Bahia. E-mail: fabiane louise@yahoo.com.br 